\title{
Modeling the monthly mean soil-water balance with a statistical-dynamical ecohydrology model as coupled to a two-component canopy model
}

\author{
J. P. Kochendorfer and J. A. Ramírez \\ Department of Civil and Environmental Engineering, Colorado State University, Ft. Collins, CO 80523, USA
}

Received: 17 January 2008 - Published in Hydrol. Earth Syst. Sci. Discuss.: 11 March 2008

Revised: 14 October 2010 - Accepted: 18 October 2010 - Published: 27 October 2010

\begin{abstract}
The statistical-dynamical annual water balance model of Eagleson (1978) is a pioneering work in the analysis of climate, soil and vegetation interactions. This paper describes several enhancements and modifications to the model that improve its physical realism at the expense of its mathematical elegance and analytical tractability. In particular, the analytical solutions for the root zone fluxes are re-derived using separate potential rates of transpiration and bare-soil evaporation. Those potential rates, along with the rate of evaporation from canopy interception, are calculated using the two-component Shuttleworth-Wallace (1985) canopy model. In addition, the soil column is divided into two layers, with the upper layer representing the dynamic root zone. The resulting ability to account for changes in root-zone water storage allows for implementation at the monthly timescale. This new version of the Eagleson model is coined the Statistical-Dynamical Ecohydrology Model (SDEM). The ability of the SDEM to capture the seasonal dynamics of the local-scale soil-water balance is demonstrated for two grassland sites in the US Great Plains. Sensitivity of the results to variations in peak green leaf area index (LAI) suggests that the mean peak green LAI is determined by some minimum in root zone soil moisture during the growing season. That minimum appears to be close to the soil matric potential at which the dominant grass species begins to experience water stress and well above the wilting point, thereby suggesting an ecological optimality hypothesis in which the need to avoid water-stress-induced leaf abscission is balanced by the maximization of carbon assimilation (and associated transpiration). Finally, analysis of the sensitivity of model-determined peak green LAI to soil texture shows that the coupled model is able to repro-
\end{abstract}

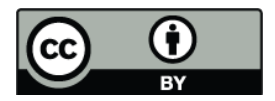

Correspondence to: J. A. Ramírez (ramirez@engr.colostate.edu) duce the so-called "inverse texture effect", which consists of the observation that natural vegetation in dry climates tends to be most productive in sandier soils despite their lower water holding capacity. Although the determination of LAI based on complete or near-complete utilization of soil moisture is not a new approach in ecohydrology, this paper demonstrates its use for the first time with a new monthly statistical-dynamical model of the water balance. Accordingly, the SDEM provides a new framework for studying the controls of soil texture and climate on vegetation density and evapotranspiration.

\section{Introduction}

In the subtropics and midlatitudes, water is the most important abiotic control on terrestrial plant productivity (Nemani et al., 2003). Consequently, a plethora of approaches have been developed to include soil-moisture limitations in terrestrial vegetation models. One of the most basic approaches is to make plant water use an increasing function of vegetation density in the form of green leaf area index (LAI) and then constrain LAI by soil moisture as available over the growing season (e.g., Kergoat, 1998; Neilson, 1995; Running and Coughlan, 1988; Woodward, 1987). Accurate modeling of water balance dynamics in the root zone is critical to such an approach. The essential feature of the dynamics is the delivery of moisture during storms and its removal during inter-storm periods. Modeling those high frequency dynamics is typically achieved with high temporal and spatial resolution (e.g., Braud et al., 1995; Federer, 1979). An alternative approach is to use analytical solutions of the governing physical equations coupled to statistical models of the climatic drivers (e.g., Eagleson, 1978a-g; Milly, 1994; Rodriguez-Iturbe et al., 1999). The

Published by Copernicus Publications on behalf of the European Geosciences Union. 
nature of such "statistical-dynamical" models makes them amenable to the quantification of variability and the propagation of uncertainty - activities that are increasingly being recognized as essential to hydrologic forecasting at climatic time scales, particularly with regard to assessing the potential impacts of climate change (e.g., Carter et al., 1999; Jones, 2000 ) - with a variety of analytical and numerical techniques such as Bayesian statistics, derived distributions and Monte Carlo simulation. Part of that nature is also to encourage parsimonious use of parameters and driving variables. From an operational standpoint, this makes a statistical-dynamical model more likely to be applicable outside of regions where and time frames when there are detailed observations of the hydroclimatic environment. For example, they can be driven by large spatial and temporal averages of precipitation such as obtained from remote sensing and climate modeling.

In this paper, we provide an overview of the formulation of the Statistical-Dynamical Ecohydrology Model (SDEM) and its coupling to the two-component (soil surface and vegetation) canopy model of Shuttleworth and Wallace (1985) The SDEM is based on the groundbreaking soil-vegetationclimate annual water balance model of Eagleson (Eagleson, 1978a-g, 2002). Eagleson (1982, 2002) and Eagleson and Tellers (1982) used the Eagleson model to explore theories of "ecological optimality," one of which hypothesizes that mean vegetation density can be predicted through the maximization of mean annual soil moisture, thereby implying a minimization of the likelihood of water stress. While it is the annual formulation of the Eagleson model and its analytical solution that allow for such a hypothesis and its examination by thorough sensitivity analysis, it is also that formulation and its lack of seasonality and the accompanying variations in soil moisture storage that make the theory troubling and difficult to validate against observations (Kerkhoff et al., 2004). To address the issue of seasonality in soil moisture and water stress, the SDEM is implemented at the monthly time scale with separate root and recharge zones. In addition it accounts for frozen soil and snow accumulation and melt. The seasonality in the model allows for application and testing of the following alternative hypothesis regarding the control that soil moisture exerts on vegetation productivity in water-limited systems: vegetation density, in the form of peak green leaf area index (LAI), is maximized for the mean water balance such that soil moisture in the latter half of the growing season just reaches the point at which water stress is experienced. In this way, the advantage of reducing exposure to water stress is balanced by the evolutionary imperative to maximize carbon assimilation (and thereby fecundity).

We examine our alternative optimality hypothesis for two grassland sites in the US Great Plains. This is done principally through an analysis of the sensitivity of modeled monthly mean root-zone soil moisture to variations in peak green LAI. We also compare model results to observations of soil moisture and the partitioning of the annual water balance. Finally, through a sensitivity analysis of model-

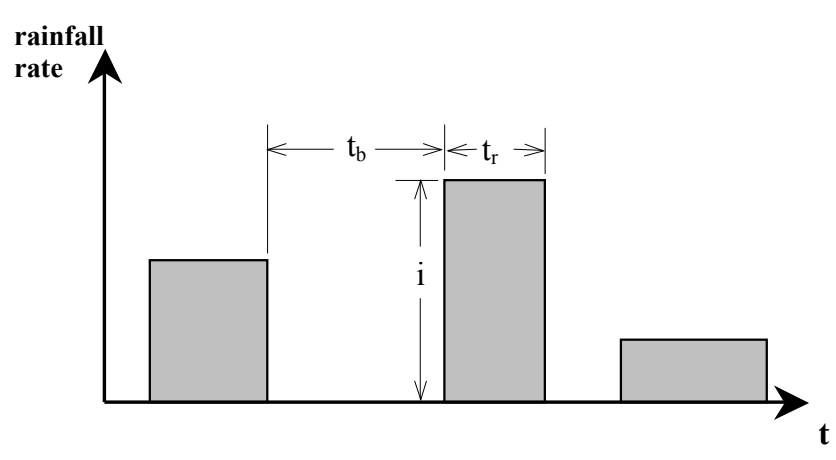

Fig. 1. The rectangular pulse model of precipitation.

determined green LAI to soil texture, we look at the role of soil texture in the partitioning of the annual water balance. Specifically, we examine whether the so-called "inverse texture effect" is observable in model results. As first elucidated by Noy-Meir (1973), the inverse texture effect explains the observation that, in dry climates, soils of high permeability tend to be more productive than soils of low permeability, despite the higher water holding capacity of the latter. According to Noy-Meier, this is primarily because low-permeability soils hold the water nearer the surface (rather than allowing it to drain deeper) where it is readily lost to soil evaporation.

In a companion paper (Kochendorfer and Ramírez, 2010), the alternative optimality hypothesis is used with the model to estimate long-term average peak green LAI and associated evapotranspiration partitioning over a domain encompassing the central United States.

\section{Overview of the original Eagleson model and its solution}

The Eagleson statistical-dynamic annual water balance model Eagleson (1978a-e) is a one-dimensional representation of soil moisture dynamics as forced by a stochastic climate. More specifically, atmospheric supply of moisture, i.e., precipitation, is modeled as rectangular pulses that arrive according to a Poisson process (Fig. 1). A single interstorm/storm event is completely described by the time between storms, $t_{\mathrm{b}}$, the storm duration, $t_{\mathrm{r}}$, and the storm intensity, $i$. The storm depth, $h\left(=i t_{\mathrm{r}}\right)$, is also an important characteristic. $t_{\mathrm{b}}, t_{\mathrm{r}}$ and $i$ are assumed to be independent and well approximated by exponential distributions. $h$ is taken to be gamma-distributed for the sake of analytical tractability. The atmospheric demand for moisture is modeled more simply as a constant rate of potential evaporation, $e_{\mathrm{p}}$. In Eagleson's original annual version, climate is taken as stationary throughout a "rainy season" in which all precipitation falls as rain.

Soil moisture dynamics at the land surface are captured using a modified version of Phillip's (1969) approximate analytical solution of the concentration-dependent diffusion 
equation (i.e., the Richards equation). Soil hydraulic properties are based on the Brooks and Corey (1966) model. Using a derived-distribution approach, the one-dimensional physical model is combined with the probability distributions of the stochastic precipitation model to arrive at expected values of single storm and inter-storm fluxes of infiltration, evaporation from the soil surface and surface retention evaporation. These values are then aggregated to annual values by multiplying by the expected number of storms over the length of the rainy season. Transpiration during inter-storm periods is linearly superimposed on the dynamics of evaporation from the soil surface and assumed to take place at a constant fraction $M k_{\mathrm{v}}$ of $e_{\mathrm{p}}$, where $M$ is the fractional vegetation coverage, and $k_{\mathrm{v}}$ is the vegetal transpiration efficiency. Similarly, recharge to groundwater is modeled as steady-state gravity drainage less hydrostatic capillary rise from a fixed water table.

Assuming no change in soil moisture storage, the mean annual soil-water balance can be written, following Hatton et al. (1997), as

$$
\begin{aligned}
& E\left[I_{\mathrm{A}}(s, \text { climate }, \text { soil })\right]= \\
& E\left[E_{\mathrm{TA}}(s, \text { climate, soil, vegetation })\right]+E\left[R_{\mathrm{gA}}(s, \text { climate, soil })\right](1)
\end{aligned}
$$

where each term has an analytical form and is dependent on soil moisture as defined by the relative soil saturation, $s$, and on a relatively small number of climate, soil and vegetation parameters. $s$ varies between zero and one and is given by

$s=\frac{\theta_{\mathrm{t}}-\theta_{\mathrm{r}}}{n_{\mathrm{t}}-\theta_{\mathrm{r}}}$

where the numerator equals the effective volumetric soil water content, $\theta$, and the denominator equals the effective porosity, $n$. Although the dependence on soil moisture of all three terms in Eq. (1) is represented by the same letter $s$, in actuality different values of $s$ at different points in time and in the soil column control the given fluxes. Namely, infiltration is dependent on $s$ at the beginning of storms, while the evaporation from the soil surface component of evapotranspiration depends on the $s$ at the beginning of interstorm periods. While these two fluxes are primarily dependent on $s$ in the upper part of the soil column, recharge to groundwater is controlled by $s$ at the bottom of the soil column. The analytical solution of all three fluxes requires an assumption of initially uniform soil moisture in a semi-infinite soil column. In order to solve Eq. (1), Eagleson (1978a) uses a single value, $s_{0}$, which the author defines to be the "temporal average of the spatial average" and which Salvucci and Entekhabi (1994a) show to be more precisely associated with the "equivalent steady-state moisture profile." With that simplification, Eq. (1) can be solved numerically for $s_{0}$. Eagleson (1978a) surmises that the use of a single value of $s$ tends to overestimate surface runoff as a result of $s_{\mathrm{O}}$ being an overestimate of the mean pre-storm soil moisture.

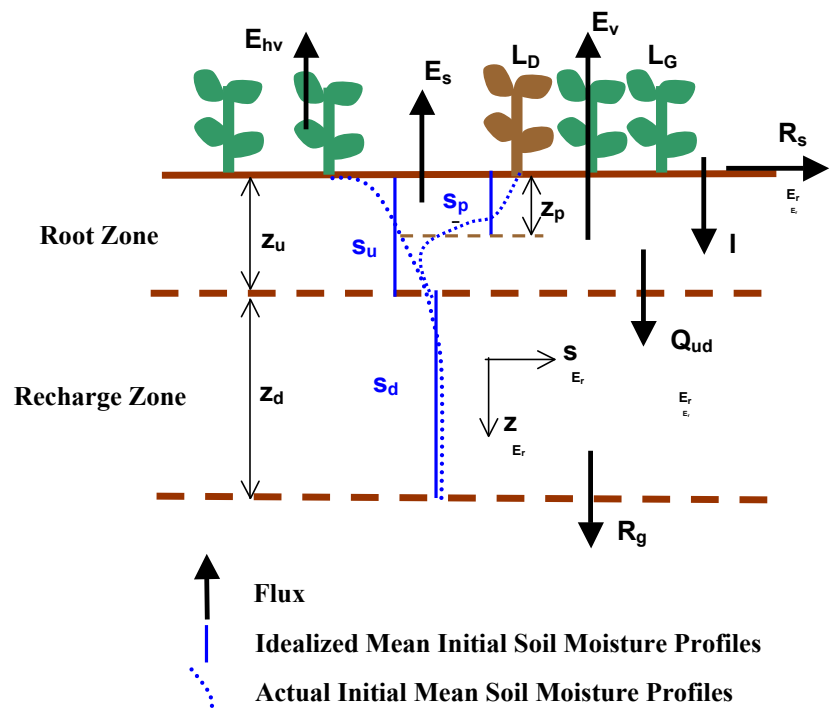

Fig. 2. Schematic of the SDEM.

\section{Overview of the statistical-dynamical ecohydrology model and its solution}

The development of the present version of the SDEM involved a top-down process of application of Eagleson's original model and successively more complicated versions to several locations in the US Great Plains with long-term records of soil moisture. Additional insight was drawn from comparisons made by Salvucci and Entekhabi (1994a, b) between solutions of Eagleson's model and numerical simulations with a finite difference model that is based on the same soil physics. The first important conclusion resulting from those analyses is that the steady-state solution of soil moisture from Eagleson's model can be a substantial overestimate of the actual temporal mean in the root zone, with the difference being greater for drier climates. This is explainable by the fact that the actual mean is less than the post-storm soil moisture, which controls evaporation from the soil surface. Closure of the water balance can only be achieved by a higher value of $s_{0}$, which serves both to decrease infiltration and to increase groundwater runoff and evaporation from the soil surface. The resulting overestimate in surface runoff is in addition to that which Eagleson realized would occur with the temporal mean. An additional observation from the work of Salvucci and Entekhabi (1994a, b) is that the mean soil moisture profile is nearly identical to the mean pre-storm profile. This is the consequence of the fact that the majority of the redistribution of soil moisture after a storm occurs within a day or two. As seen below, an assumption that the mean prestorm soil moisture is equal to the temporal mean is used in the solution of the SDEM.

The structure and main variables of the SDEM developed in this paper are illustrated in Fig. 2. The primary parameters of the model are listed in Table 1 . The soil column has been 
Table 1. Main parameters of the statistical-dynamical ecohydrology model.

\begin{tabular}{lll}
\hline Symbol & Description & Units \\
\hline evapotranspiration: & & \\
$e_{\mathrm{ps}}$ & mean rate of potential evaporation from the soil surface & $\mathrm{cm} /$ day \\
$e_{\mathrm{pv}}$ & mean rate of potential transpiration & $\mathrm{cm} /$ day \\
$e_{\mathrm{hv}}$ & mean rate of evaporation from vegetal interception & $\mathrm{cm} /$ day \\
$h_{\mathrm{V}}$ & vegetal interception capacity & $\mathrm{cm}$ \\
$\psi_{\mathrm{uc}}$ & critical root-zone soil matric potential (i.e., the value of $\psi\left(s_{\mathrm{u}}\right)$ & $\mathrm{cm}$ \\
& at which the vegetation begins to experience water stress) & \\
$\psi_{\mathrm{lc}}$ & critical leaf water potential (equivalent to the wilting point & $\mathrm{cm}$ \\
& matric potential in the root zone) & \\
precipitation: & mean storm duration & \\
$m_{\mathrm{tr}}$ & mean duration of interstorm periods & days \\
$m_{\mathrm{tb}}$ & mean storm intensity & days \\
$m_{\mathrm{i}}$ & mean storm depth & $\mathrm{cm} /$ day \\
$m_{\mathrm{h}}$ & parameter of the gamma distribution of storm depth & $\mathrm{cm}$ \\
$k$ & & dimensionless \\
soil: & saturated hydraulic conductivity & \\
$K_{\mathrm{S}}$ & bubbling soil matric potential & $\mathrm{cm} /$ day \\
$\psi_{\mathrm{S}}$ & pore size distribution index & $\mathrm{cm}$ \\
$m$ & effective porosity & dimensionless \\
$n$ & thickness of soil layer & dimensionless \\
$z$ & length of the month & $\mathrm{cm}$ \\
other: & mean air temperature & \\
$\tau$ & & days \\
\hline
\end{tabular}

divided into root (upper) and recharge (deep) zones, with mean monthly values of soil moisture of $s_{\mathrm{u}}$ and $s_{\mathrm{d}}$, respectively. $s_{\mathrm{d}}$ is assumed to be uniform with depth and to vary slowly on a seasonal cycle. As noted above, the highly dynamic nature of the root zone requires consideration of not only the temporal mean value of soil moisture in that zone but also the mean values prior to storm and inter-storm periods. Eagleson's (1978c) analytical solution of the Richards equation uses the assumption of initially uniform soil moisture in a semi-infinite soil column. As long as the bottom of the root zone is deeper than the average penetration depth of the wetting and drying fronts during storm and inter-storm periods, respectively, the semi-infinite assumption is reasonably satisfied. However, the presence of wetting and drying fronts implies non-uniform initial conditions. During periods of soil moisture recharge, the temporal mean of soil moisture generally decreases with depth, and the assumption of a uniform initial profile will tend to underestimate surface runoff. In contrast, during periods of soil moisture depletion, soil moisture generally increases with depth, and the assumption leads to overestimating runoff. More significant, however, is the pronounced wetting front that is usually present at the end of storms. The estimation of a mean penetration depth for the wetting front, $z_{\mathrm{p}}$ (over which infiltration is averaged to obtain $s_{\mathrm{p}}$, the mean post-storm soil moisture) is described in the next section.
Another major difference of the SDEM with Eagleson's original model is that evaporation from the soil surface and transpiration are treated as coupled processes above the soil surface. Vegetation is conceptualized as being distributed evenly across the land, with bare soil interspersed between individual plants or small clumps of plants - as opposed to non-interacting fractions of the land surface. As a result, available energy is relatively homogeneously distributed across the land surface at the scale of the stand, such that one can define a point near the canopy top where there is a combined flow of latent and sensible heat from the two surfaces. We thus make use of the quantity $e_{\mathrm{ps}}$, the rate of potential evaporation from the soil surface in the presence of the given density of vegetation - in contrast to Eagleson's use of $e_{\mathrm{p}}$, which is that in the absence of vegetation (i.e., $M=0$ ). Likewise, we define $e_{\mathrm{pv}}$ as the potential rate of transpiration from the given density of vegetation, as opposed to Eagleson's definition as the rate for a closed canopy (i.e., $M=1$ ). To estimate both potential rates, we use a two-component evaporation model (Shuttleworth and Wallace, 1985) in which leaf area index (LAI) is the principal measure of vegetation density. In order to simplify use of the separate rates, we assume that surface retention of precipitation occurs significantly only on vegetation in the form of interception. In contrast, Eagleson treats surface retention as occurring at the same depth over both vegetation and bare soil. 
A final difference is that the present formulation does not account for interaction with the groundwater table. Although it would be easy enough to include capillary rise from a fixed water table in the manner of Eagleson (1978c), the need to determine a temporally and spatially representative water table depth introduces additional difficulties. In places where the water table is largely below the recharge zone, we might assume that it is in unconsolidated parent material with low capillarity. In places where the water table is frequently in the recharge zone or higher, the model will underestimate $s_{u}$ and, consequently, evapotranspiration and surface runoff. Surface runoff will also be underestimated by virtue of the fact that, as in Eagleson's (1978e) original formulation, it is modeled as occurring only by the Hortonian (i.e., infiltration excess) mechanism. In general, the one-dimensional form of the model is a significant limitation to the modeling of runoff processes at larger than point scales.

Following Eagleson, we write equations for the soil water balance in terms of expected values of the relevant fluxes. Crucial additions are snow storage at the surface and moisture storage in both soil layers. The water balance of the snowpack during month $i$ is given by

$$
\Delta S_{i}=f_{s_{i}} E\left[P_{i}\right]-E\left[W_{i}\right]
$$

The water balance in the root zone during month $i$ is defined by

$$
\begin{aligned}
& n_{\mathrm{u}} z_{\mathrm{u}} \Delta s_{\mathrm{u}_{i}}= \\
& E\left[I_{i}\left(s_{\mathrm{u}_{i}}\right)\right]-E\left[E_{\mathrm{v}_{i}}\left(s_{\mathrm{u}_{i}}\right)\right]-E\left[E_{s_{i}}\left(s_{\mathrm{p}_{i}}\right)\right]-E\left[Q_{\mathrm{ud}_{i}}\left(s_{\mathrm{u}_{i}}, s_{\mathrm{d}_{i}}\right)\right]
\end{aligned}
$$

The water balance in the recharge zone is

$$
n_{\mathrm{d}} z_{\mathrm{d}} \Delta s_{\mathrm{d}_{i}}=E\left[Q_{\mathrm{ud}_{i}}\left(s_{\mathrm{u}_{i}}, s_{\mathrm{d}_{i}}\right)\right]-E\left[R_{\mathrm{g}_{i}}\left(s_{\mathrm{d}_{i}}\right)\right]
$$

As noted in Sect. 2, expected annual values of the water balance fluxes in the original Eagleson model are found by numerically solving for $s_{0}$, the value of $s$ that closes the water balance. Our monthly, two-layer version can be solved in a similar manner. The task is of course much more complex, given values for $s$ must be found and the water balance closed for two soil layers in each of twelve different months. A solution scheme was developed to do just that using mean monthly values of the climate variables, storm statistics and green LAI. In each month, values of $s_{\mathrm{u}}$ and $s_{\mathrm{d}}$ are found such that the changes in storage from the beginning to the end of the month are equal to the net of the fluxes in and out of the two soil layers. The annual water balance is closed by solving for values of $s_{\mathrm{u}}$ and $s_{\mathrm{d}}$ for January which are returned for the subsequent "thirteenth" month through solution of the intervening monthly water balances.

\section{Expected values of water balance fluxes}

In this section, the equations that govern the expected values of the fluxes in and out of the two soil layers are pre- sented. The focus is on equations unique to the present version of the model. Accordingly, the reader is referred to Eagleson (1978a-e) for detailed derivations of equations that are similar to or unchanged from the original model. The flux calculations use six evapotranspiration parameters, five precipitation parameters and five soil parameters for each soil layer (Table 1). In addition, air temperature is used in the modeling of snow accumulation and melt and soil freezing. As in Sect. 3, the subscripts $u$ and $d$ on the soil parameters refer to values for the root and recharge zones, respectively. For the sake of notational parsimony, flux rates and soil moisture are not indexed by month in the remainder of this paper. Likewise, all climate parameters have monthly varying values but are not indexed. On the other hand, all soil parameters are assumed temporally invariant.

\subsection{Snow accumulation and melt}

We model snow accumulation and melt more simply and deterministically than we do rainfall. Specifically, we use a temperature index methodology. During months in which the mean temperature is below $-4^{\circ} \mathrm{C}$, all precipitation during the month is assumed to be snow. When the mean temperature is above $6^{\circ} \mathrm{C}$, all precipitation is taken to be rain. Between the two temperatures, precipitation is linearly fractionated between snow and rain such that

$f_{\mathrm{s}}=\left\{\begin{array}{lrl}1, & T & \leq-4^{\circ} \mathrm{C} \\ (6-T) / 10, & -4^{\circ} \mathrm{C}<T<6^{\circ} \mathrm{C} \\ 0, & T & \geq 6^{\circ} \mathrm{C}\end{array}\right.$

Snowmelt is assumed to occur whenever $T$ is above $-4{ }^{\circ} \mathrm{C}$. The rate of snowmelt is taken to be $0.5 \mathrm{~cm}$ per ${ }^{\circ} \mathrm{C}$ above that temperature and to occur for a maximum of three consecutive days. All of the snow that falls in a given month is made available for melt in that month. Thus,

$E[W]= \begin{cases}0, & T \leq-4^{\circ} \mathrm{C} \\ \min \left\{S+f_{\mathrm{s}} E[P], 1.5(4+T)\right\}, & T>-4^{\circ} \mathrm{C}\end{cases}$

\subsection{Groundwater recharge}

As in Eagleson (1978c), percolation to groundwater is modeled as steady-state gravity flow. Thus groundwater recharge is simply equal to the hydraulic conductivity in the recharge zone. Using the Brooks and Corey (1966) formulation of the dependency of the unsaturated hydraulic conductivity on $s$ gives

$E\left[R_{\mathrm{g}}\right]=\tau K_{\mathrm{sd}} s_{\mathrm{d}}^{\mathrm{c}_{\mathrm{d}}}$

where $c$ is the pore disconnectedness index, which the authors show to be related to the pore size distribution index by

$c=\frac{2+3 m}{m}$ 

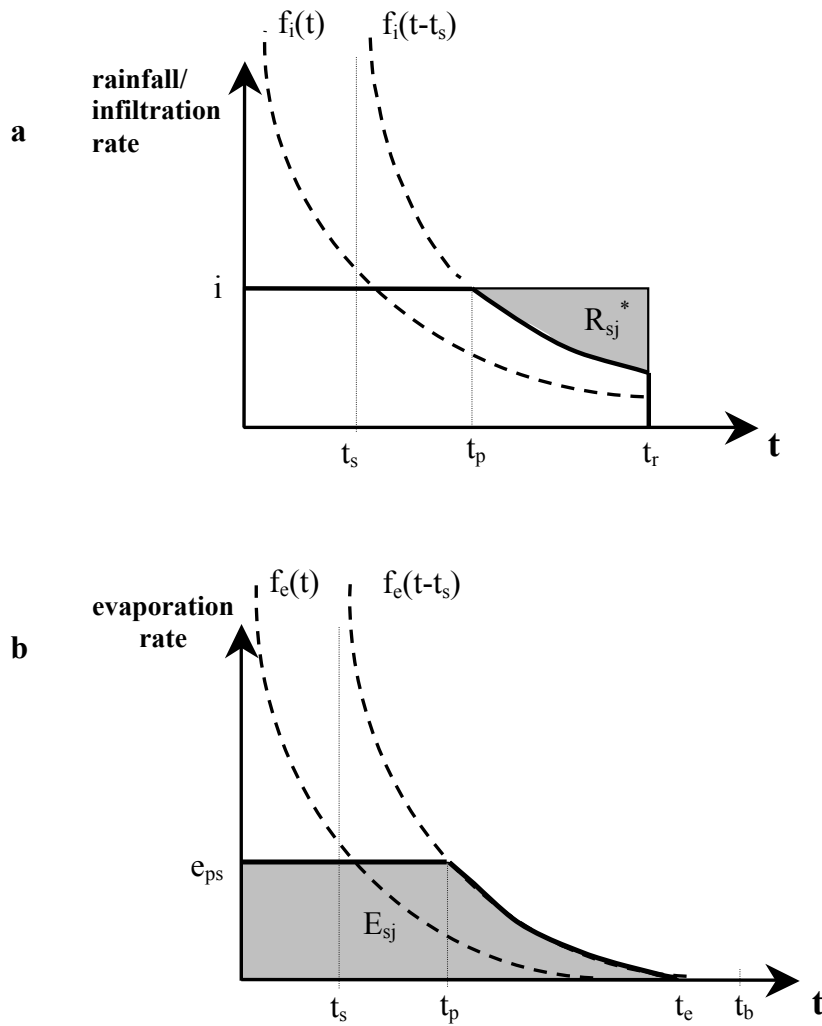

Fig. 3. The dynamics of: (a) infiltration, and (b) evaporation from the soil surface.

\subsection{Flow between soil layers}

We assume that the moisture flux between the root zone and the recharge zone is in sufficient quasi-steady state at the monthly time scale such that Darcy's Law for unsaturated flow is applicable. Ideally, we would use the values of the hydraulic conductivity and the gradient of matric potential at the interface of the two soil layers. However, because the interface is actually an ill-defined transition zone, we use the mean value of $s$ in each layer. The hydraulic conductivity is then estimated as the geometric mean of $K_{\mathrm{u}}\left(s_{\mathrm{u}}\right)$ and $K_{\mathrm{d}}\left(s_{\mathrm{d}}\right)$. For estimation of the gradient of the matric potential, we take $\Psi_{\mathrm{u}}\left(s_{\mathrm{u}}\right)$ and $\Psi_{\mathrm{d}}\left(s_{\mathrm{d}}\right)$ to be separated by a distance of $\frac{1}{2}$ $\left(z_{\mathrm{u}}+z_{\mathrm{d}}\right)$. For the expected value of flow between soil layers during the given month, this gives

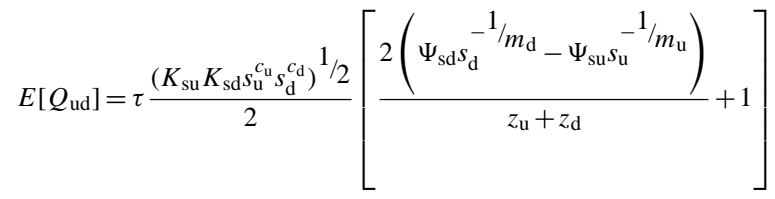

where the dependencies of hydraulic conductivity and matric potential on $s$ are those of Brooks and Corey (1966).

\subsection{Infiltration and surface runoff}

Figure 3a illustrates how surface runoff from a single rectangular pulse of rainfall is modeled. $f_{\mathrm{i}}(t)$ is the infiltration capacity and is based on Philip's approximate analytical solution of the Richards equation (Eagleson, 1978c):

$f_{i}(t)=1 / 2 S_{i} t^{-1 / 2}+A_{\mathrm{o}}$

where

$A_{\mathrm{o}}=1 / 2 K_{\mathrm{su}}\left(1+s_{\mathrm{u}}^{c_{\mathrm{u}}}\right)$

and $S_{\mathrm{i}}$ is the effective infiltration sorptivity $\left(\mathrm{cm} /\right.$ day $\left.^{1 / 2}\right)$ over the range of $s_{\mathrm{u}}$ to one for the relative soil saturation. Salvucci and Entekhabi (1994b) argue that Eagleson's (1978c) equation for $S_{\mathrm{i}}$ does not account for the infinite diffusivity that develops at $s=1$. In their use of the model, they include a modification to $S_{\mathrm{i}}$ suggested by Philip (1958) that gives

$S_{i}=\left[2 n_{\mathrm{u}} K_{\mathrm{su}} \Psi_{\mathrm{su}}\left(1-s_{\mathrm{u}}\right)\left(1+\frac{10\left(1-s_{\mathrm{u}}\right) \phi_{i}\left(s_{\mathrm{u}}, m_{\mathrm{u}}\right)}{3 m_{\mathrm{u}} \pi}\right)\right]^{1 / 2}$

where $\phi_{\mathrm{i}}\left(s_{\mathrm{u}}, m_{\mathrm{u}}\right)$ is the dimensionless effective infiltration diffusivity, for which Eagleson (1982) uses the approximation,

$\phi_{i}\left(s_{\mathrm{u}}, m_{\mathrm{u}}\right)=\left[5 / 3+\left(1 / m_{\mathrm{u}}+2\right)\left(1-s_{\mathrm{u}}\right)^{1.425-0.0375\left(1 / m_{\mathrm{u}}+2\right)}\right]^{-1}$

The soil surface becomes saturated and runoff begins when the infiltration capacity falls below the intensity of the storm, $i$. The time at which this occurs, $t_{\mathrm{p}}$, is referred to as the ponding time and is typically estimated using the time compression approximation (TCA) (Salvucci and Entekhabi, 1994a). As shown in Fig. 3, the TCA consists of shifting the infiltration capacity curve to the right by an amount $t_{\mathrm{s}}$, such that the area beneath the shifted curve from $t_{\mathrm{s}}$ to $t_{\mathrm{p}}$ is equal to $i t_{\mathrm{p}}$, the depth of infiltrated rainfall at $t_{\mathrm{p}}$. Once runoff begins at $t_{\mathrm{p}}$, rainfall excess, $R_{\mathrm{s} j}^{*}$, is generated by the given storm (indexed as $j$ ) from that point until the storm ends at $t_{\mathrm{r}}$. Through approximate integration of the joint probability distribution of $i$ and $t_{\mathrm{r}}$ (which under the assumption of the independence of $i$ and $t_{\mathrm{r}}$ is simply the product of the two exponential distributions) over the domain of $R_{\mathrm{s} j}^{*}$, Eagleson (1978e) derives a probability distribution for $R_{\mathrm{s} j}^{*}$, which, in the absence of capillary rise, has as its mean

$E\left[R_{\mathrm{s} j}^{*}\right]=m_{i} m_{\mathrm{tr}} e^{-2 \sigma-A_{\mathrm{o}} / m_{i}} \Gamma(\sigma+1) \sigma^{-\sigma}$

where $\sigma$ is defined by

$\sigma=\frac{1}{2}\left(\frac{S_{i}^{2}}{m_{\mathrm{tr}} m_{i}^{2}}\right)^{1 / 3}$

In Fig. 3 and in the derivation of Eq. (15), it is assumed that the time it takes to fill surface retention is negligible. 
In order to account for the volumetric effect of surface retention, Eagleson (1978e) takes the expected value of surface runoff to be the difference between Eq. (15) and the expected value of evaporation from surface retention. Tellers and Eagleson (1980) observe that this counts surface retention against only storms producing runoff. They propose setting the rainfall excess equal to surface runoff and subtracting surface retention from infiltration. Doing that and using a set of relationships that stem from the assumption of the independence of $i, t_{\mathrm{r}}$ and $t_{\mathrm{b}}$,

$m_{\mathrm{h}}=m_{i} m_{\mathrm{tr}}$

$m_{v}=\frac{\tau}{m_{\mathrm{tr}}+m_{\mathrm{tb}}}$

$E[P]=m_{v} m_{\mathrm{h}}$

where $m_{v}$ is the mean number of storms in the given month, we can use Eq. (15) to write a surface runoff ratio for rainfall:

$\frac{E\left[R_{\mathrm{S}}\right]}{\left(1-f_{\mathrm{S}}\right) E[P]}=e^{-2 \sigma-A_{\mathrm{o}} / m_{i}} \Gamma(\sigma+1) \sigma^{-\sigma}, f_{\mathrm{s}}<1$

The $1-f_{\mathrm{s}}$ factor has been applied in Eq. (20) under the simplifying assumption that, in months with both snow and rainfall, the two types of precipitation occur in separate periods, with the length of the snow period given by $f_{\mathrm{s}} \tau$. Furthermore, rain-on-snow events at the transition from a snow to a rain period are not explicitly considered. We do, however, consider the general possibility of surface runoff from snowmelt by applying the dynamic model for rain depicted in Fig. 3. The total snowmelt for the month is assumed to occur in a single pulse with duration up to 3 days, such that

$i_{\mathrm{w}}=0.5(T+4)$

$t_{\mathrm{rw}}=\min \left\{E(W) / i_{\mathrm{w}}, 3\right\}$

where $i_{\mathrm{w}}$ and $t_{\mathrm{rw}}$ are the intensity (cm/day) and duration (days) of the snowmelt pulse, respectively. The expected depth of runoff from the pulse is given by Eq. (15):

$E\left[R_{\mathrm{w}}\right]=R_{\mathrm{s} j}^{*}\left(i_{\mathrm{w}}, t_{\mathrm{rw}}, s_{\mathrm{u}}\right)$

A consideration for both snowmelt and rainfall is whether infiltration occurs into frozen soil. A temperature index approach is taken here as well, such that whenever the sum of the mean temperatures of the given month and the previous month is below $0^{\circ} \mathrm{C}$, the following correction factor devised by Rawls and Brakensiek (1985) is applied to the hydraulic conductivity of the root zone soil:

$C_{\mathrm{fs}}= \begin{cases}2.0-1.9 \frac{s_{\mathrm{u}}}{s_{33}}, & s_{\mathrm{u}}<s_{33} \\ 0.1, & s_{\mathrm{u}} \geq s_{33}\end{cases}$

where $s_{33}$ is the effective soil saturation in the root zone at a matric potential of $33 \mathrm{kPa}(=337 \mathrm{~cm})$.
Subtracting snowmelt and rainfall runoff, along with interception loss, from the inputs to infiltration gives the expected value of infiltration during the given month as

$E[I]=\left(1-f_{\mathrm{s}}\right) E[P]+E[W]-E\left[R_{\mathrm{s}}\right]-E\left[R_{\mathrm{W}}\right]-E\left[E_{\mathrm{hv}}\right]$

where $E_{\mathrm{hv}}$ is evaporation from canopy interception. An equation for $E\left[E_{\mathrm{hv}}\right]$ is presented in the next section.

The final quantity that must be estimated for our model of infiltration dynamics is the mean penetration depth of wetting fronts, over which the expected value of infiltration is distributed. Eagleson (1978c) approximates mean penetration depths based on the sum of a diffusive component and a gravity drainage component. The diffusive component is taken from the analytical solution of the Richards equation, with the standard assumptions of constant diffusivity, $D$, initially uniform soil moisture, $\theta_{\mathrm{i}}$, and a different, but constant soil moisture at the surface, $\theta_{\mathrm{o}}$. That solution is

$\frac{\theta-\theta_{\mathrm{o}}}{\theta_{i}-\theta_{\mathrm{o}}}=\operatorname{erf}\left[\frac{z}{2(D t)^{1 / 2}}\right]$

For the purposes of estimating how deep the water table must be for the assumption of a semi-infinite soil column to be satisfied, Eagleson sets the argument of the error function in Eq. (26) equal to two. At that value, the error function evaluates to 0.995 , meaning that, at the corresponding depth $z, \theta$ is only slightly perturbed away from $\theta_{\mathrm{i}}$ and towards $\theta_{\mathrm{o}}$. In the case of infiltration, a penetration depth so estimated would be at the asymptotic tail of the wetting front and typically on the order of the root zone depth or greater. In order to provide a penetration depth more suitable to our purposes, we set the argument of the error function equal to one, at which the error function evaluates to 0.84 . We thus rewrite Eagleson's equation for the penetration depth as:

$z_{\mathrm{p}}=2\left(D_{i} m_{\mathrm{tr}}\right)^{1 / 2}+\frac{m_{\mathrm{t}_{\mathrm{r}}} K_{\mathrm{su}}}{n_{\mathrm{u}}}$

where $D_{i}$ is the effective infiltration diffusivity $\left(\mathrm{cm}^{2} /\right.$ day), which Eagleson (1978c) derives as

$D_{i}=\frac{5 K_{\mathrm{su}} \Psi_{\mathrm{su}} \phi_{i}\left(s_{\mathrm{u}}, m_{\mathrm{u}}\right)}{3 m_{\mathrm{u}} n_{\mathrm{u}}}$

With a value for $z_{\mathrm{p}}$ determined, the mean post-storm relative soil saturation is calculated as

$s_{\mathrm{p}}=s_{\mathrm{u}}+\frac{E[I]}{n_{\mathrm{u}} z_{\mathrm{p}}}$

\subsection{Evaporation from bare soil}

As illustrated in Fig. 3b, the rate of exfiltration by evaporation from the soil surface is estimated in a manner analogous to the infiltration rate. The analog to rainfall with constant intensity is a constant rate of potential evaporation, $e_{\mathrm{ps}}$. Initially evaporation proceeds at $e_{\mathrm{ps}}$. This is typically referred to as "stage-one" or "climate-controlled" evaporation. At time 
$t_{\mathrm{p}}$, the maximum rate at which the soil can deliver moisture (i.e., the exfiltration capacity), $f_{\mathrm{e}}(t)$, drops below $e_{\mathrm{ps}}$. Beyond $t_{\mathrm{p}}$, evaporation proceeds at the rate determined by $f_{\mathrm{e}}(t)$ and is referred to as "stage-two" or "soil-controlled" evaporation. At time $t_{\mathrm{e}}, f_{\mathrm{e}}(t)$ reaches zero and evaporation from the soil surface ceases. The process can be cut short at any point by the end of the inter-storm period defined by $t_{\mathrm{b}}$. In the manner of the infiltration process, $t_{\mathrm{p}}$ is estimated using the TCA via a time shift in $f_{\mathrm{e}}(t)$ of $t_{\mathrm{s}}$. Following Eagleson (1978d), we derive an expected value for evaporation from the soil surface during the $j$ inter-storm period by integrating the product of the volume of the evaporation from the soil surface and the probability distribution of $t_{\mathrm{b}}$ over the three domains of $t_{\mathrm{b}}$ (i.e., $t_{\mathrm{b}} \leq t_{\mathrm{p}}, t_{\mathrm{p}}<t_{\mathrm{b}} \leq t_{\mathrm{e}}$ and $t_{\mathrm{e}}<t_{\mathrm{b}}$ ):

$$
\begin{aligned}
& E\left[E_{\mathrm{s} j}\right]=\int_{0}^{t_{\mathrm{p}}} e_{\mathrm{ps}} t_{\mathrm{b}} f_{T_{\mathrm{b}}}\left(t_{\mathrm{b}}\right) d t_{\mathrm{b}} \\
& +\int_{t_{\mathrm{p}}}^{t_{\mathrm{e}}}\left(e_{\mathrm{ps}} t_{\mathrm{p}}+\int_{t_{\mathrm{p}}}^{t_{\mathrm{b}}} f_{\mathrm{e}}\left(t-t_{\mathrm{s}}\right) d t\right) f_{T_{\mathrm{b}}}\left(t_{\mathrm{b}}\right) d t_{\mathrm{b}} \\
& +\int_{t_{\mathrm{e}}}^{\infty}\left(e_{\mathrm{ps}} t_{\mathrm{p}}+\int_{t_{\mathrm{p}}}^{t_{\mathrm{e}}} f_{\mathrm{e}}\left(t-t_{\mathrm{s}}\right) d t\right) f_{T_{\mathrm{b}}}\left(t_{\mathrm{b}}\right) d t_{\mathrm{b}}
\end{aligned}
$$

The exponential distribution of $t_{\mathrm{b}}$ is

$$
f_{T_{\mathrm{b}}}\left(t_{\mathrm{b}}\right)=\frac{e^{-\frac{t_{\mathrm{b}}}{m_{\mathrm{tb}}}}}{m_{\mathrm{tb}}}
$$

The formulation of Eq. (30) is greatly simplified by the fact that we do not include an initial period of evaporation from surface retention, as does Eagleson (1978d).

Based on an exact solution of the differential equation for the analogous problem of heat conduction in solids (Carslaw and Jaeger, 1959), Eagleson (1978c) presents an equation for the exfiltration capacity, under the absence of gravity and with the root sink being evenly distributed over the root zone:

$$
f_{\mathrm{e}}(t)=1 / 2 S_{\mathrm{e}} t^{-1 / 2}-\left(2 e_{\mathrm{v}} / z_{\mathrm{u}}\right)\left(D_{\mathrm{e}} t / \pi\right)^{1 / 2}
$$

Entekhabi and Eagleson (1989) derive the exfiltration sorptivity as

$S_{\mathrm{e}}=2 s_{\mathrm{p}}^{\frac{1}{2 m_{\mathrm{u}}}}+2\left[\frac{8 n_{\mathrm{u}} m_{\mathrm{u}} K_{\mathrm{su}} \Psi_{\mathrm{su}}}{3\left(1+3 m_{\mathrm{u}}\right)\left(1+4 m_{\mathrm{u}}\right)}\right]^{1 / 2}$

The effective exfiltration diffusivity is related to the exfiltration sorptivity by (Eagleson, 1978c):

$D_{\mathrm{e}}=\pi\left(\frac{S_{\mathrm{e}}}{2 n_{\mathrm{u}} s_{\mathrm{d}}}\right)^{2}$

Eagleson (1978c) states that the first term on the RHS of Eq. (32) is about two orders of magnitude greater than the second for typical parameter values. However, the second term grows with $t$ (as the first term decreases) and can be comparable in size to the first term when $t \geq m_{t b}$. After dropping the second term, Eagleson goes on to include a negative $e_{\mathrm{v}}$ term. This implicitly assumes that the vegetation extracts moisture at the surface, as opposed to evenly throughout the root zone. More realistic than either assumption is one of extraction from the root zone in proportion to the density of root mass. It is typical to assume root density decreases exponentially with depth (e.g., Jackson et al., 1996). Using the solution for the heat-conduction problem with a sink of exponentially distributed intensity derived by Carslaw and Jaeger (1959), we formulate the exfiltration capacity function as

$$
f_{\mathrm{e}}(t)=1 / 2 S_{\mathrm{e}} t^{-1 / 2}-e_{\mathrm{v}}\left\{1-e^{\alpha^{2} D_{\mathrm{e}} t} \operatorname{erfc}\left[\left(\beta^{2} D_{\mathrm{e}} t\right)^{1 / 2}\right]\right\}
$$

where $\beta$ is the decay constant for the root density. If the depth of the root zone is taken to be that which contains $95 \%$ of the root mass, it can be shown that

$\beta=-\frac{\ln [0.05]}{z_{\mathrm{u}}}$

We note that neither Eq. (35) nor Eagleson's (1978c) final formulation of the exfiltration capacity function includes a gravity-drainage component (which would be included in a complete solution of the problem.) Even with its neglect of the flow between the root and recharge zones, Eq. (35) is of a form that does not allow for analytical evaluation of Eq. (30). However, Eq. (32) does lead to an analytical solution. We use that knowledge, plus the fact that the second term of Eq. (35) is generally greater than the second term of Eq. (32) but less than $e_{\mathrm{v}}$, to approximate the second term of Eq. (35) with a weighted sum of the second term of Eq. (32) and $e_{\mathrm{v}}$ :

$f_{\mathrm{e}}(t) \cong 1 / 2 S_{\mathrm{e}} t^{-1 / 2}-(1-w) e_{\mathrm{v}}-w\left(2 e_{\mathrm{v}} / z_{\mathrm{u}}\right)\left(D_{\mathrm{e}} t / \pi\right)^{1 / 2}$

where $w$ is the weight. We solve for $w$, by setting Eq. (35) and Eq. (37) equal at $t=\mathrm{m}_{\mathrm{tb}}$. Along with Eq. (36), this leads to

$w=\frac{e^{x} \operatorname{erfc}\left[x^{1 / 2}\right]}{1+\frac{2 x^{1 / 2}}{\sqrt{\pi} \ln [0.05]}}$

where

$x=\frac{\ln ^{2}[0.05] D_{\mathrm{e}} m_{\mathrm{tb}}}{z_{\mathrm{u}}^{2}}$

In Fig. $4, w$ is plotted as a function of $x$. A minimum of 0.685 is reached at $x=1.10$. $w$ subsequently increases, reaching one again at $x=3.88$. At greater values of $x$, Eq. (35) is greater than Eq. (32) when $t=m_{\mathrm{tb}}$. Consequently, $w$ is held at one when $x$ exceeds 3.88. Such cases are rare because they generally involve large values of both $D_{\mathrm{e}}$ and $m_{\mathrm{tb}}$; because $D_{\mathrm{e}}$ is an increasing function of $s$, large values of $m_{\mathrm{tb}}$ imply relatively small values of $D_{\mathrm{e}}$ for a given soil. 
With Eq. (37) as the exfiltration capacity curve and Eq. (34) substituted in, Eq. (30) evaluates to

$$
\begin{aligned}
& E\left[E_{\mathrm{s} j}\right]=m_{\mathrm{tb}} e_{\mathrm{ps}}+1 / 2 S_{\mathrm{e}}\left(\pi m_{\mathrm{tb}}\right)^{1 / 2}\left(1-\frac{w e_{\mathrm{v}} m_{\mathrm{tb}}}{n_{\mathrm{u}} z_{\mathrm{u}} s_{\mathrm{p}}}\right) \\
& \left\{\operatorname{erf}\left[\left(\frac{t_{\mathrm{e}}-t_{\mathrm{s}}}{m_{\mathrm{tb}}}\right)^{1 / 2}\right]-\operatorname{erf}\left[\left(\frac{t_{\mathrm{p}}-t_{\mathrm{s}}}{m_{\mathrm{tb}}}\right)^{1 / 2}\right]\right\} e^{-\frac{t_{\mathrm{s}}}{m_{\mathrm{tb}}}} \\
& -m_{\mathrm{tb}}\left\{e_{\mathrm{ps}}+e_{\mathrm{v}}\left[1-w+\frac{w S_{\mathrm{e}}}{n_{\mathrm{u}} z_{\mathrm{u}} s_{\mathrm{p}}}\left(t_{\mathrm{p}}-t_{s}\right)^{1 / 2}\right]\right\} e^{-\frac{t_{\mathrm{p}}}{m_{\mathrm{tb}}}} \\
& +m_{\mathrm{tb}} e_{\mathrm{v}}\left\{1-w+\frac{w S_{\mathrm{e}}}{n_{\mathrm{u}} z_{\mathrm{u}} s_{\mathrm{p}}}\left(t_{\mathrm{e}}-t_{\mathrm{s}}\right)^{1 / 2}\right\} e^{-\frac{t_{\mathrm{e}}}{m_{\mathrm{tb}}}}
\end{aligned}
$$

From the TCA,

$t_{\mathrm{p}}=\frac{1}{e_{\mathrm{ps}}}\left\{S_{\mathrm{e}}\left(t_{\mathrm{p}}-t_{\mathrm{s}}\right)^{1 / 2}-\frac{2 w e_{\mathrm{v}} S_{\mathrm{e}}}{3 n_{\mathrm{u}} z_{\mathrm{u}} S_{\mathrm{p}}}\left(t_{\mathrm{p}}-t_{\mathrm{s}}\right)^{3 / 2}-(1-w) e_{v}\left(t_{\mathrm{p}}-t_{\mathrm{s}}\right)\right\}$

where

$t_{\mathrm{p}}-t_{\mathrm{s}}=\left\{\frac{\left[\left(e_{\mathrm{ps}}+(1-w) e_{\mathrm{v}}\right)^{2}+\frac{2 w e_{\mathrm{v}} S_{\mathrm{e}}{ }^{2}}{n_{\mathrm{u}} z_{\mathrm{p}} s_{\mathrm{p}}}\right]^{1 / 2}-e_{\mathrm{ps}}-(1-w) e_{\mathrm{v}}}{\frac{2 w e_{\mathrm{v}} S_{\mathrm{e}}}{n_{\mathrm{u}} z_{\mathrm{u}} s_{\mathrm{p}}}}\right\}^{2}$

$t_{\mathrm{p}}$ substituted back into Eq. (42) yields $t_{s}$. Setting $f_{\mathrm{e}}\left(t_{\mathrm{e}}-t_{s}\right)$ equal to zero gives

$t_{\mathrm{e}}=t_{\mathrm{s}}+\left\{\frac{\left[(1-w)^{2} e_{\mathrm{v}}^{2}+\frac{2 w e_{\mathrm{v}} S_{\mathrm{e}}^{2}}{n_{\mathrm{u}} z_{\mathrm{p}}}\right]^{1 / 2}-(1-w) e_{\mathrm{v}}}{\frac{2 w e_{\mathrm{v}} S_{\mathrm{e}}}{n_{\mathrm{u}} z_{\mathrm{u}} s_{\mathrm{p}}}}\right\}^{2} t_{\mathrm{p}}$

The expected value of total evaporation from bare soil during the given month is simply the product of Eq. (40) and the mean number of interstorm periods:

$E\left[E_{\mathrm{s}}\right]=\left(1-f_{\mathrm{s}}\right) m_{v} E\left[E_{\mathrm{s} j}\right]$

where we have again applied the assumption of the separation of snow and rain periods within the month. We further assume that in months when the soil is frozen, evaporation is zero regardless of the partitioning of precipitation between snow and rain.

\subsection{Evaporation from canopy interception}

Eagleson (1978d) derives the expected value of evaporation from surface retention by integrating the product of the volume of evaporation from surface retention and the joint probability distribution of $h$ and $t_{\mathrm{b}}$ over two domains of $h\left(0<h<h_{\mathrm{v}}\right.$ and $\left.h \geq h_{\mathrm{v}}\right)$ and two of $t_{\mathrm{b}}\left(0<t_{\mathrm{b}}<h / e_{\mathrm{hv}}\right.$ and $\left.t_{\mathrm{b}} \geq h / e_{\mathrm{hv}}\right)$.

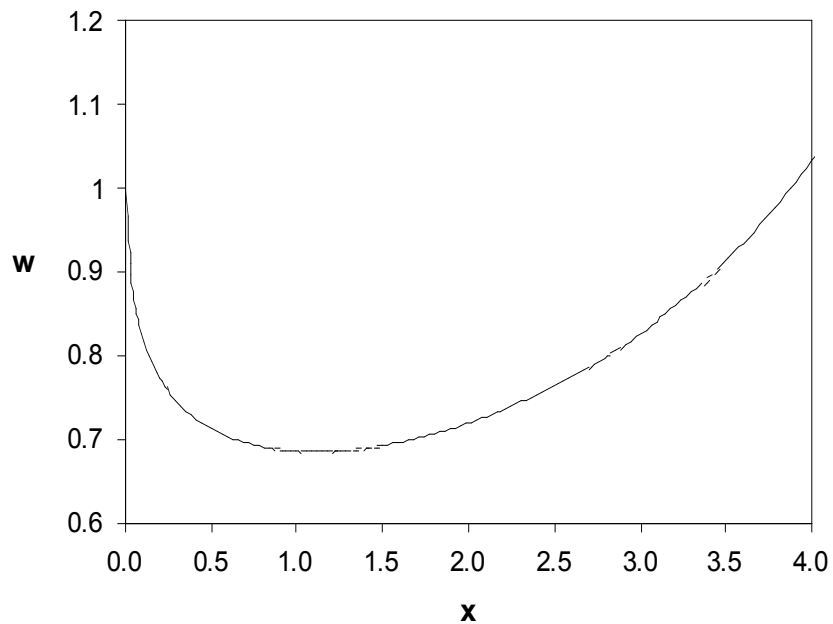

Fig. 4. Weighting factor applied to the two versions of the second term of exfiltration capacity curve.

Allowing for our assumption that all surface retention is vegetal interception, the result is

$$
\begin{aligned}
& E\left[E_{\mathrm{hv} j}\right] \\
& =m_{\mathrm{tb}} e_{\mathrm{hv}}\left\{1-\left(1-\frac{\gamma\left[\kappa, \frac{\kappa h_{\mathrm{v}}}{m_{h}}\right]}{\Gamma[\kappa]}\right) e^{-\frac{h_{\mathrm{v}}}{m_{\mathrm{tb}} h_{\mathrm{hv}}}}-\frac{\gamma\left[\kappa, \frac{\kappa h_{\mathrm{v}}}{m_{h}}+\frac{h_{\mathrm{v}}}{m_{\mathrm{bb}} e_{\mathrm{hv}}}\right]}{\Gamma[\kappa]}\left(1+\frac{m_{\mathrm{h}}}{\kappa m_{\mathrm{tb}} e_{\mathrm{hv}}}\right)^{-\kappa}\right\}
\end{aligned}
$$

For typical climates and values of $h_{\mathrm{v}}$, most storms will fill the interception capacity and most inter-storm periods will last long enough to evaporate all of the interception, such that Eq. (45) will not be much less than $h_{\mathrm{v}}$. The expected value of total evaporation from interception for the given month is the expectation for a single inter-storm period times the expected number of inter-storm periods:

$E\left[E_{\mathrm{hv}}\right]=\left(1-f_{\mathrm{s}}\right) m_{v} E\left[E_{\mathrm{hv} j}\right]$

Although sublimation from intercepted snow can be significant, particularly from the canopy of conifer forests, we take no account of it. Likewise, sublimation from the snowpack is not considered. Rather, all snowfall contributes to the snowpack at the soil surface and subsequently infiltrates into the soil or runs off during snowmelt. For estimation of the interception capacity of the canopy for rainfall, we assume that it is proportional to the area of all vegetation surfaces, such that

$h_{\mathrm{v}}=0.02 L_{\mathrm{T}}$

where $L_{\mathrm{T}}$ is the total leaf area index. The factor of 0.02 is primarily based on a compendium of literature values of $h_{\mathrm{V}}$ presented by Rutter (1975), with consideration of the potential for additional intra-storm evaporation from interception. 


\subsection{Transpiration}

Transpiration is assumed to take place at the potential rate $e_{\mathrm{pv}}$ unless the vegetation is under moisture stress. To estimate the reduction of transpiration due to moisture stress, we employ a framework outlined by Eagleson (1978d), but ultimately not employed in his model. The framework often attributed to Cowan (1965), following the work of Gardner (1960) and van den Honert (1948) treats the soil-vegetation component of the soil-vegetation-atmosphere continuum as an analog of Ohm's Law of electricity. More specifically, the flow of liquid water between the pore spaces in the soil and the cell walls of the internal pore spaces of the leaves is assumed proportional to the potential difference and inversely proportional to the resistance to flow between the two points. Using that formulation, Kochendorfer (2005) derives an equation for the matric potential in the root zone at which the vegetation experiences water stress:

$\Psi_{\mathrm{uc}}=\Psi_{\mathrm{lc}}-2 e_{\mathrm{pv}} R_{\mathrm{v}} / t_{\mathrm{d}}$

Values of resistances for individual plants are found throughout the literature in a variety of units. Converting those values to values of $R_{\mathrm{v}}$ for stands of vegetation requires knowledge or assumptions about leaf, stem and root densities. In general, the greater the vegetation density the lower is the resistance. At the same time, increasing vegetation density increases the transpiratory demand. Furthermore, the climatic factors that determine the potential rate of transpiration are also major determinants of the speciation and morphology of the vegetation. Rather than try to capture the complex interactions that go into determining $R_{\mathrm{v}}$, we assume that the second term of Eq. (48) is relatively invariant within given climatic regions and/or vegetation classes at the time of the year when water stress is most likely to occur. That assumption allows us to assign directly values of $\Psi_{\mathrm{uc}}$, for which there are numerous observations in the literature. Assuming fixed values of $\Psi_{\mathrm{uc}}$ is fairly common in the modeling of evapotranspiration (Guswa et al., 2002). Also typical is to assume that the rate of evapotranspiration or transpiration decreases linearly with soil moisture between $s_{\mathrm{uc}}$ and the wilting point. That assumption gives

$e_{\mathrm{v}}= \begin{cases}e_{\mathrm{pv}}, & s_{\mathrm{u}} \geq s_{\mathrm{uc}} \\ \frac{s_{\mathrm{u}}-s_{\mathrm{w}}}{s_{\mathrm{uc}}-s_{\mathrm{w}}} e_{\mathrm{pv}}, & s_{\mathrm{w}}<s_{\mathrm{u}}<s_{\mathrm{uc}} \\ 0, & s_{\mathrm{u}} \leq s_{\mathrm{w}}\end{cases}$

where $s_{\mathrm{W}}$ is the relative soil saturation at the permanent wilting point.

In order to estimate the expected value of total transpiration for the given month, we assume that transpiration does not take place until all intercepted precipitation is evaporated following the termination of a storm:

$E\left[E_{\mathrm{v}}\right]=\left(1-f_{\mathrm{s}}\right)\left(m_{\mathrm{tb}}-m_{\mathrm{th}}\right) m_{v} e_{\mathrm{v}}$

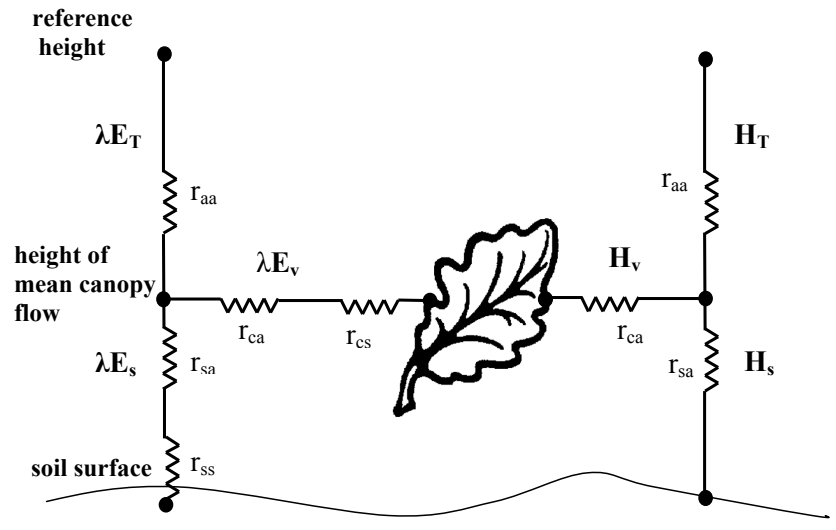

Fig. 5. Schematic of the Shuttleworth-Wallace (1985) twocomponent canopy model.

where $\mathrm{m}_{\mathrm{th}}$ is the mean time (days) it takes for interception to evaporate and is given by

$m_{\mathrm{th}}=\frac{E\left[E_{\mathrm{hv} j}\right]}{e_{\mathrm{hv}}}$

\section{Potential rates of evaporation and transpiration}

The coupling of transpiration and soil evaporation above the soil surface is captured through application of the Shuttleworth-Wallace (SW) model of evapotranspiration from sparse crops (Shuttleworth and Wallace, 1985). The SW model is a one-dimensional energy combination model, similar in form to the better-known Penman-Monteith (PM) model (Monteith, 1965). Like the PM model, the SW model employs the concept of aerodynamic and surface resistances, but, unlike the PM model, the SW model divides the land surface into a coupled, two-component system comprised of the soil surface and the vegetation canopy (Fig. 5). The coupling occurs principally through the division of available energy between the two surfaces and the combination of the sensible and latent heat fluxes from the two surfaces at a hypothetical point of "mean canopy flow." With estimation of the vapor pressure deficit at that point, the PM equation can be applied to each flux separately. The potential rates of evaporation from the soil surface and transpiration are thus given by

$e_{\mathrm{ps}}=\frac{f_{\mathrm{c}}}{\lambda} \frac{\Delta A_{\mathrm{s}}+\rho c_{\mathrm{p}} D_{\mathrm{o}} / r_{\mathrm{as}}}{\Delta+\gamma\left(1+r_{\mathrm{ss}} / r_{\mathrm{as}}\right)}$

$e_{\mathrm{pv}}=\frac{f_{\mathrm{c}}}{\lambda_{\mathrm{LH}}} \frac{\Delta\left(A-A_{\mathrm{s}}\right)+\rho c_{\mathrm{p}} D_{\mathrm{o}} / r_{\mathrm{ac}}}{\Delta+\gamma\left(1+r_{\mathrm{sc}} / r_{\mathrm{ac}}\right)}$

We can also approximate the rate of evaporation from vegetal interception with

$e_{\mathrm{hv}}=e_{\mathrm{pv}} \mid r_{\mathrm{sc}}=0$ 
In the same manner that the PM equation is derived (i.e., by substituting the resistance-based flux equations for sensible and latent heat into the energy balance equation), Shuttleworth and Wallace (1985) show that

$$
D_{\mathrm{o}}=D+\left[\Delta A-(\Delta+\gamma) \lambda E_{\mathrm{T}}\right] r_{\mathrm{aa}} / \rho c_{\mathrm{p}}
$$

The presence of the $\lambda_{\mathrm{T}}$ term in Eq. (55) means that a rigorous solution of Eqs. (52)-(54) requires simultaneous solution of actual evapotranspiration. To avoid a large number of iterations of the model and to preserve our treatment of the potential rates as external drivers of the water balance, we exploit the knowledge that, due the relative size of $r_{\mathrm{aa}}, D_{\mathrm{o}}$ does not deviate much from $D$. We thereby first approximate $\lambda E_{\mathrm{T}}$ in each month using the water balance model and $D_{\mathrm{o}}=D$ in Eqs. (52) and (53). These values are then substituted into Eq. (55) to obtain approximations of $D_{\mathrm{o}}$, which are then updated with each iteration in the solution of the coupled models. Such an approach is consistent with the limited representativeness of observed values of $D$; the meteorological stations where humidity measurements are made are often well removed from the dominant vegetation of the region. In addition, we are using averages of $D$ over the entire month, whereas the most appropriate values would be the averages over just the periods in which evaporation from the soil surface and transpiration actually occur at their respective potential rates. $D$ tends to be lower at those times because they immediately follow rainstorms, and because there is a negative feedback of humidity to potential evapotranspiration.

Related to the issue of the value of $D$ is the use of $r_{\mathrm{ss}}$ in Eq. (52). If Eq. (52) were used to estimate the rate of stage-two evaporation, $r_{\mathrm{ss}}$ would be the resistance to vapor flow between the point in the subsurface where the soil air is saturated and the surface. As such, it would need to be modeled as an increasing function of the drying process (e.g., Camillo and Gurney, 1986; Choudhury and Monteith, 1988; Stannard, 1993). Although an implicit or explicit assumption of most formulations of potential evaporation is that the soil column is moist enough that the air at the soil surface is saturated (i.e., $r_{\mathrm{ss}}=0$ ), we (via unpublished analysis), along with others (Camillo and Gurney, 1986; Sellers et al., 1992), have found that a significant non-zero value of $r_{\mathrm{ss}}$ is needed to predict accurately evaporation from well watered soils. This may be a case of imprecision in the rubric of potential evaporation as applied to pre-stage-two evaporation (e.g., Brutsaert and Chen, 1995; Van Bavel and Hillel, 1976) or simply modeling error, such as that induced by use of the monthly average of $D$. It may also represent actual resistances imposed by soil crusting or the mulching effect of plant litter. Bond and Willis (1969), for example, found that moderate amounts of straw (as low as $560 \mathrm{~kg} / \mathrm{ha}$ ) significantly reduced stage-one evaporation from experimental soil columns. Although use of a non-zero $r_{\mathrm{ss}}$ for stage-one evaporation will necessarily be imprecise, we include small (relative to those representative of mid-to-late stage-two evaporation), fixed values in the calculation of $e_{\mathrm{ps}}$.
The available energy terms in Eqs. (52), (53) and (54) are estimated from the surface energy balance using standard assumptions as outlined in Sellers (1965). In particular, The net radiation at the soil surface is estimated from the net radiation over the entire land surface using a Beer's Law relationship:

$R_{\mathrm{ns}}=R_{\mathrm{n}} \exp \left(-\mu L_{\mathrm{T}}\right)$

where $L_{\mathrm{T}}$ is the sum of the leaf area index of transpiring green vegetation, $L_{\mathrm{G}}$, and that of non-transpiring components of the canopy, $L_{\mathrm{D}}$. To estimate $L_{\mathrm{D}}$, we assume that it consists of: (1) a persistent part, mainly live and dead woody stems and other supporting tissue, but also (especially in grasslands and wetlands) some standing-dead herbaceous matter that takes a long time to decay or to be eaten, and (2) senescent and dead leaves after peak greenness is reached. The first component is taken as a fixed fraction of peak green LAI. For the second, we borrow the assumption by Sellers et al. (1996) that the decrease in LAI caused by dead and dying leaves remains for one month (before the leaves fall off or are eaten.) The formulation for $L_{\mathrm{D}}$ can then be written as

$L_{D_{i}}= \begin{cases}f_{\mathrm{p}} L_{\mathrm{Gp}}, & L_{\mathrm{G}_{i}} \geq L_{\mathrm{G}_{i-1}} \\ f_{\mathrm{p}} L_{\mathrm{Gp}}+\left(L_{\mathrm{G}_{i-1}}-L_{\mathrm{G}_{i}}\right), & L_{\mathrm{G}_{i}}<L_{\mathrm{G}_{i-1}}\end{cases}$

Shuttleworth and Wallace (1985) estimate the two aerodynamic resistances in Eqs. (52), (53) and (55) as linear combinations of the values for bare soil (i.e., $L_{\mathrm{T}}=0$ ) and a closed canopy (i.e., $L_{\mathrm{T}} \geq 4$ ):

$r_{\mathrm{aa}}= \begin{cases}1 / 4 L_{\mathrm{T}} r_{\mathrm{aa}}(4)+1 / 4\left(4-L_{\mathrm{T}}\right) r_{\mathrm{aa}}(0), & 0 \leq L_{\mathrm{T}} \leq 4 \\ r_{\mathrm{aa}}(4), & L_{\mathrm{T}}>4\end{cases}$
$r_{\mathrm{as}}= \begin{cases}1 / 4 L_{\mathrm{T}} r_{\mathrm{as}}(4)+1 / 4\left(4-L_{\mathrm{T}}\right) r_{\mathrm{as}}(0), & 0 \leq L_{\mathrm{T}} \leq 4 \\ r_{\mathrm{as}}(4), & L_{\mathrm{T}}>4\end{cases}$

The authors derive the closed canopy aerodynamic resistances by assuming neutral stability, such that, above the canopy, the eddy diffusion coefficient increases in proportion to the product of the friction velocity and the height above the zero plane displacement, while below the canopy, it increases exponentially with height. They integrate the corresponding equations, first from the soil surface to the height of mean canopy flow and then from the height of mean canopy flow to the reference height, to obtain

$$
\begin{aligned}
& r_{\mathrm{as}}(4)= \\
& \frac{\ln \left[\left(x_{\mathrm{r}}-d\right) / z_{\mathrm{o}}\right]}{k^{2} u} \frac{h_{\mathrm{c}}}{n_{e}\left(h_{\mathrm{c}}-d\right)}\left\{\exp n_{\mathrm{e}}-\exp \left[n_{\mathrm{e}}\left\{1-\left(d+z_{\mathrm{o}}\right) / h_{\mathrm{c}}\right\}\right]\right\} \\
& r_{\mathrm{aa}}(4)= \\
& \left\{\frac{\ln \left[\left(x_{\mathrm{r}}-d\right) / z_{\mathrm{o}}\right]}{k^{2} u} \ln \left[(x-d) /\left(h_{\mathrm{c}}-d\right)\right]+\frac{h_{\mathrm{c}}}{n_{\mathrm{e}}\left(h_{\mathrm{c}}-d\right)}\left(\exp \left[n_{\mathrm{e}}\left\{1-\left(d+z_{\mathrm{o}}\right) / h_{\mathrm{c}}\right\}\right]-1\right)\right\}
\end{aligned}
$$


The height of mean canopy flow is taken as $d+z_{o}$. The zero plane displacement and roughness length are assumed to be a fixed fraction of the canopy height:

$d=0.63 h_{\mathrm{c}}$

$z_{\mathrm{o}}=0.13 h_{\mathrm{c}}$

The bare soil aerodynamic resistances are estimated by splitting the total bare soil aerodynamic resistance (i.e., that between the soil surface and reference height) at the height of mean canopy flow:

$r_{\mathrm{aa}}(0)=\ln ^{2}\left[\mathrm{x} / z_{\mathrm{os}}\right] / k^{2} u-r_{\mathrm{as}}(0)$

$r_{\mathrm{as}}(0)=\ln \left[\mathrm{x} / z_{\mathrm{os}}\right] \ln \left[\left(d+z_{\mathrm{o}}\right) / z_{\mathrm{os}}\right] / k^{2} u$

where $z_{\mathrm{os}}$, the roughness length of the soil surface, typically assumed to be $0.01 \mathrm{~m}$.

Finally, the bulk resistances in Eqs. (52) and (53) must also be integrations over the whole canopy. Stomatal resistance generally decreases with increasing shortwave irradiance and, therefore, increases with depth into the canopy. Woodward (1987) proposes the following hyperbolic relationship:

$r_{\mathrm{s}}=r_{\mathrm{s} \min }+\frac{b}{S_{\mathrm{r}}}$

The author gives a value of $29500 \mathrm{sm}^{-1} \mathrm{Wm}^{-2}$ for $b$. By conceptualizing differential horizontal layers of the canopy as resistances in parallel, we can integrate the inverse of Eq. (66) over the canopy to obtain the inverse of the bulk stomatal resistance (i.e., the canopy conductance.) If we apply Beer's Law to the extinction of $S_{\mathrm{r}}$ through the canopy and assume that transpiring and non-transpiring LAI are distributed vertically in proportion to one other, we can perform the integration over $L_{\mathrm{G}}$ as

$\mathrm{r}_{\mathrm{sc}}^{-1}=\int_{0}^{L_{\mathrm{G}}}\left(r_{\mathrm{s}_{\min }}+\frac{b}{S_{\mathrm{r}}} e^{\frac{\mu_{L_{\mathrm{T}}}}{L_{\mathrm{G}}} l_{\mathrm{G}}}\right)^{-1} d l_{\mathrm{G}}$

which evaluates to

$\mathrm{r}_{\mathrm{sc}}=\frac{\mathrm{r}_{\mathrm{s}_{\text {min }}}}{L_{\mathrm{G}}}\left(1+\frac{\ln \left[\mathrm{r}_{\mathrm{s}_{\text {min }}}+b / S_{\mathrm{r}}\right]-\ln \left[\mathrm{r}_{\mathrm{s}_{\text {min }}}+\left(b / S_{\mathrm{r}}\right) e^{\mu L_{\mathrm{T}}}\right]}{\mu L_{\mathrm{T}}}\right)^{-1}$

A similar approach can be applied to the increase of leafboundary-layer resistance as the windspeed decreases with depth in the canopy. Choudhry and Monteith (1988) combine assumptions of (1) an exponential decrease in windspeed with height, and (2) proportionality of leaf-boundary-layer resistance to the inverse of the square root of windspeed, to obtain

$\mathrm{r}_{\mathrm{ac}}=\frac{1}{L_{\mathrm{G}}}\left\{\frac{0.02}{n_{\mathrm{w}}}\left(\frac{u_{\mathrm{c}}}{w_{1}}\right)^{1 / 2}\left(1-\exp \left[-\frac{n_{\mathrm{w}}}{2}\right]\right)\right\}^{-1}$
For the windspeed decay constant, we use an empirical dependency on LAI developed by Lafleur and Rouse (1990) from evapotranspiration measurements in a subarctic wetland:

$n_{\mathrm{w}}=2.6 L_{\mathrm{T}}^{0.36}$

Although Eq. (70) may not be representative of other biomes, $r_{\mathrm{ac}}$ is generally small relative to $r_{\mathrm{sc}}$ and therefore does not have to be estimated with great accuracy.

\section{Application of the coupled models to two grassland sites}

The SDEM and its coupling to the SW model were developed and tested using soil, vegetation and climate data for several sites - two of which are covered by native grasses - in the US Great Plains with relatively long-term records of soil moisture. The first grassland site is the Central Plains Experimental Range (CPER) in north-central Colorado. Singh et al. (1998) measured soil moisture by neutron probe from 1985 to 1992 in order to study the long-term dynamics and spatial variation of soil moisture across soil textures and slope positions in this USDA-ARS shortgrasssteppe research site. For the sandy-loam (the soil texture that predominates at the CPER) site, we averaged the soil moisture data across the three slope positions (upland, midslope and lowland). The resulting monthly values for the root and recharge zone are depicted in Fig. $6 \mathrm{a}-\mathrm{b}$. The root zone was defined as the top $50 \mathrm{~cm}$ based on the finding by field measurements of Lee and Lauenroth (1994) that the dominant grass at the CPER, Bouteloua gracilis, has over $80 \%$ of its roots in the top $50 \mathrm{~cm}$. The recharge zone was defined as the next $50 \mathrm{~cm}$.

The location of the second set of soil moisture data is the R-5 experimental watershed near Chickasha, Oklahoma. This moderately grazed, 24.7-acre watershed is covered by mixed, native grasses on silt loam soils. It was maintained by the USDA-ARS as part of the Southern Great Plains Research Watershed (USDA-ARS, 1983). Loague (1992) provides graphical and tabular summary of soil moisture data collected by gravimetric and neutron-probe techniques over two multi-year periods spanning 1966 to 1974 . Measurement locations in the watershed vary from four in the first period to 34 in the second period. The watershed-average values of root- and recharge-zone soil moisture are depicted in Fig. 6c$\mathrm{d}$, where we took the root and recharge zone depths to be $65 \mathrm{~cm}$ each to account for the likely greater root depths of the mixed grasses.

\subsection{Parameter values and climate variables}

The Brooks-Corey parameters (Table 2) used in the SDEM are those from Rawls et al. (1982) for the corresponding soil texture, with exception of saturated hydraulic conductivities, which are geometric means of the values from 


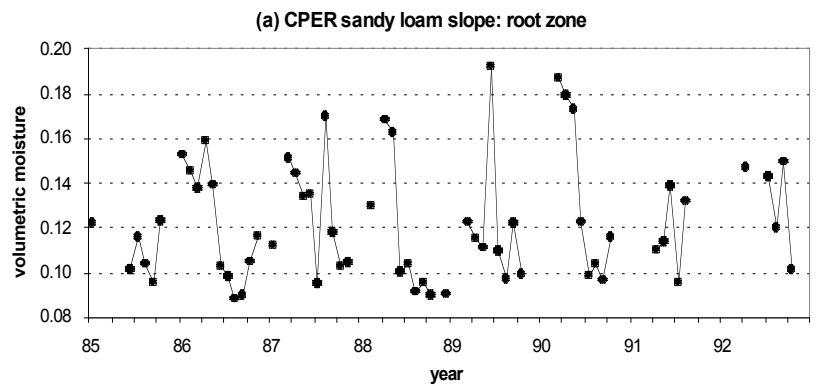

(b) CPER sandy loam slope: recharge zone

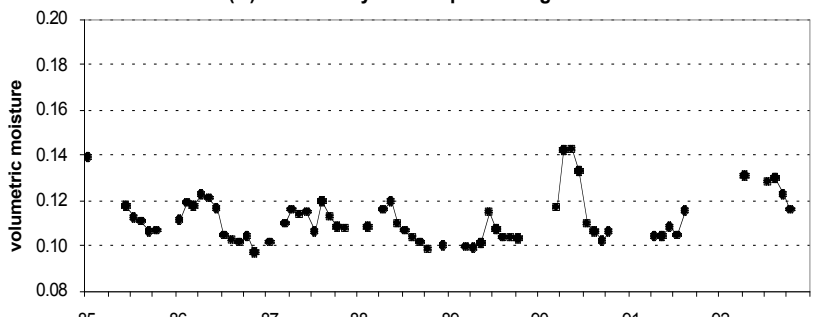

(c) R-5 watershed: root zone
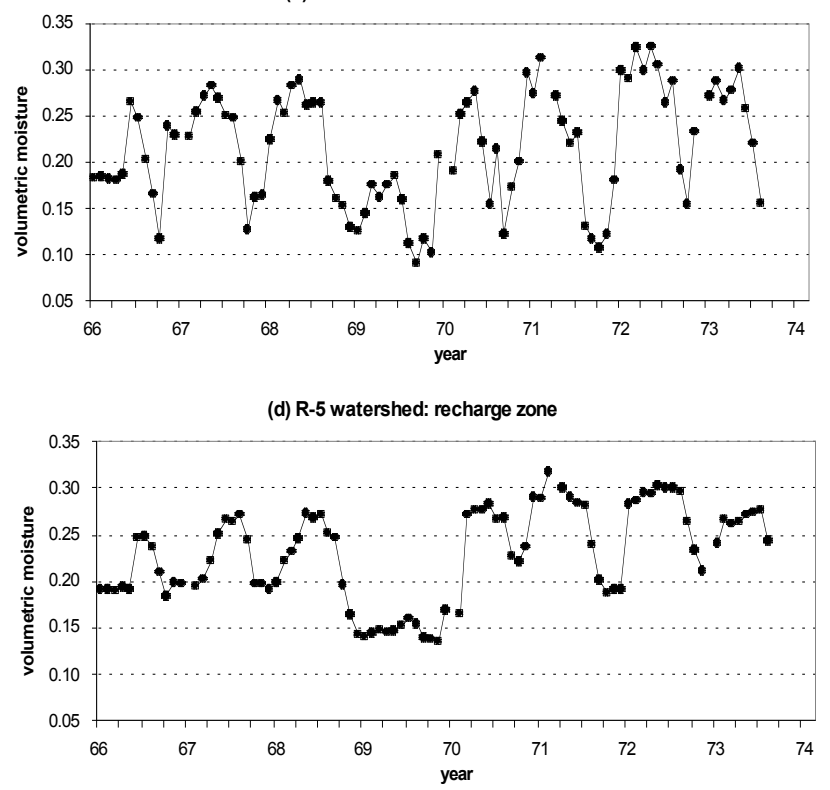

Fig. 6. Monthly averages of observed volumetric soil moisture at the two grassland sites: (a) root zone at the CPER (measurements made at depths of 30 and $45 \mathrm{~cm}$ ), (b) recharge zone at the CPER (measurements made at depths of 60,75 and $90 \mathrm{~cm}$, (c) root zone at the R-5 watershed (measurements made at depths of 15, 30, 45 and $60 \mathrm{~cm}$ ), and (d) recharge zone at the R-5 watershed (measurements made at depths of 75, 90, 105 and $120 \mathrm{~cm}$ ).

Rawls et al. (1982) and Cosby et al. (1984). We note that site-specific data on soil hydraulic properties are available for both sites (e.g., Luxmoore and Sharma, 1980). However, efforts to use those data did not produce substantially better results. For $\Psi_{\mathrm{lc}}$ and $\Psi_{\mathrm{uc}}$, we used values $10000 \mathrm{~cm}$ and $25000 \mathrm{~cm}$, respectively. Those values are primarily based on the work of Sala et al. (1981), who made leaf water potential and conductance measurements of Bouteloua gracilis during an artificially extended period of soil moisture dry-down at the CPER. Bouteloua gracilis is also a major species in the R-5 watershed.

In addition to monthly green LAI, values of seven timeinvariant, vegetation-specific parameters are necessary for implementation of the SW model as described in Sect. 5. Parameter values, and citations for their sources, for twelve classes of vegetation - including grasslands that are predominantly composed of species that use the $\mathrm{C}_{3}$ and $\mathrm{C}_{4}$ photosynthetic pathways - can be found in Kochendorfer and Ramírez (2010). The phenology (seasonal progression) of green LAI (Fig. 8) is based on Knight (1973) and Hazlett (1992) for the CPER site, and Ritchie et al. (1976) for the R-5 watershed. The LAI measurements made by Hazlett also include standing dead LAI and thus were the basis for setting $f_{\mathrm{p}}=0.3$. Values of canopy height $\left(h_{\mathrm{c}}=50 \mathrm{~cm}\right)$ and leaf width $\left(w_{1}=1 \mathrm{~cm}\right)$ are based on the values used in the SiB2 (Sellers et al., 1996) and BATS (Dickinson et al., 1993) SVATS. Beer's law extinction coefficient $(\mu=0.45)$ and the eddy diffusion decay constant for the closed canopy $\left(n_{\mathrm{e}}=2\right)$ are based on several sources in the plant physiology literature. $r_{\mathrm{ss}}$ and $r_{\mathrm{smin}}$, were also initially based on the SVATS and plant physiology literature. Very little data is available for $r_{\mathrm{ss}}$ (mainly by inference), while a wide range of values for $r_{\mathrm{smin}}$ for a variety of vegetation types can be found in the literature. Kochendorfer and Ramírez (2010) describe how the two parameters were adjusted within their a priori bounds by matching modeled and observed contours of annual streamflow over the Central US. In this paper, we use the resulting $r_{\mathrm{ss}}$ value for $\mathrm{C}_{4}$ grasses of $100 \mathrm{sm}^{-1}$. Likewise, the resulting value of $400 \mathrm{sm}^{-1}$ for $r_{\mathrm{smin}}$ in $\mathrm{C}_{4}$ grasslands was used for the R-5 watershed. On the other hand, an $r_{\mathrm{smin}}$ value of $300 \mathrm{sm}^{-1}$ was used for the CPER to reflect the greater proportion of $\mathrm{C}_{3}$ grasses at this location.

For the central US, Kochendorfer (2005) derived monthly values for the statistics of the Poisson Rectangular Pulse (PRP) stochastic precipitation model (see Sect. 2) over a half-degree grid from hourly observations of precipitation taken from 1949 to 1998 by a variety of weather stations. Kochendorfer and Ramírez (2010) provide an overview of the derivation and maps of the results. For application of the SDEM to the two grassland sites, the statistics for the grid cell in which the given site falls were used (Tables 3 and 4). For monthly values of $E[P]$, we used the 19511980 averages for the corresponding grid cell in the database for the Vegetation/Ecosystem Modeling and Analysis Project (VEMAP) (Kittel et al., 1995). The VEMAP database, along with other data sources, also provided the climate variables necessary to implement the SW model for the calculation of potential rates of transpiration, evaporation from the soil surface and evaporation from canopy interception as described in Sect. 5. A brief discussion of the datasets and how they were used to estimate monthly values of the potential rates over the half-degree grid can be found in Kochendorfer and 
Table 2. Values of soil hydraulic parameters.

\begin{tabular}{|c|c|c|c|c|c|c|c|c|c|}
\hline \multirow{4}{*}{$\begin{array}{l}\text { USDA } \\
\text { Texture Class }\end{array}$} & \multirow{3}{*}{\multicolumn{2}{|c|}{$\begin{array}{c}\text { Midpoint on } \\
\text { USDA Triangle } \\
\text { (Cosby et al., 1984) }\end{array}$}} & & & & & \multicolumn{3}{|c|}{$\mathrm{K}_{\mathrm{S}}(\mathrm{cm} /$ day $)$} \\
\hline & & & \multicolumn{4}{|c|}{$\begin{array}{l}\text { Brooks-Corey Parameters } \\
\text { (Rawls et al. 1982) }\end{array}$} & \multirow{3}{*}{$\begin{array}{l}\text { Rawls } \\
\text { et al. } \\
(1982)\end{array}$} & \multirow{3}{*}{$\begin{array}{l}\text { Cosby } \\
\text { et al. } \\
(1984)\end{array}$} & \multirow{3}{*}{$\begin{array}{l}\text { Geo } \\
\text { metric } \\
\text { mean }\end{array}$} \\
\hline & & & \multicolumn{2}{|c|}{ Arithmetic Mean } & \multicolumn{2}{|c|}{ Geometric Mean } & & & \\
\hline & $\%$ Sand & \%Clay & $n_{\mathrm{t}}$ & $\theta_{\mathrm{r}}$ & $\Psi_{\mathrm{S}}(\mathrm{cm})$ & $m$ & & & \\
\hline sand & 92 & 3 & 0.437 & 0.020 & 7.26 & 0.592 & 504 & 421 & 461 \\
\hline sandy loam & 58 & 10 & 0.453 & 0.041 & 14.7 & 0.322 & 62 & 45 & 53 \\
\hline silt loam & 17 & 13 & 0.501 & 0.015 & 20.8 & 0.211 & 16 & 24 & 20 \\
\hline clay loam & 32 & 34 & 0.464 & 0.075 & 25.9 & 0.194 & 5.5 & 21 & 11 \\
\hline silty clay & 6 & 47 & 0.479 & 0.056 & 34.2 & 0.127 & 2.2 & 12 & 5.0 \\
\hline
\end{tabular}

Table 3. PRP Model Statistics for the CPER.

\begin{tabular}{lllllll}
\hline Month & $\begin{array}{l}m_{\mathrm{tr}} \\
(\text { days })\end{array}$ & $\begin{array}{l}m_{\mathrm{tb}} \\
(\text { days })\end{array}$ & $\begin{array}{l}m_{i} \\
(\mathrm{~cm} / \text { days })\end{array}$ & $\begin{array}{l}m_{\mathrm{h}} \\
(\mathrm{cm})\end{array}$ & $k$ & $\begin{array}{l}E[P] \\
(\mathrm{cm})\end{array}$ \\
\hline Jan & 0.288 & 10.0 & 2.48 & 0.319 & 1.18 & 0.75 \\
Feb & 0.312 & 9.30 & 2.43 & 0.329 & 1.25 & 0.79 \\
Mar & 0.326 & 5.61 & 2.64 & 0.480 & 0.627 & 2.03 \\
Apr & 0.362 & 4.95 & 3.01 & 0.644 & 0.635 & 3.69 \\
May & 0.357 & 3.82 & 3.94 & 0.824 & 0.541 & 6.14 \\
Jun & 0.346 & 4.73 & 4.61 & 0.842 & 0.521 & 4.73 \\
Jul & 0.152 & 3.91 & 5.95 & 0.612 & 0.557 & 4.26 \\
Aug & 0.187 & 4.91 & 5.35 & 0.633 & 0.527 & 3.90 \\
Sep & 0.336 & 6.86 & 3.92 & 0.699 & 0.706 & 2.57 \\
Oct & 0.350 & 9.08 & 3.28 & 0.654 & 0.736 & 2.21 \\
Nov & 0.300 & 7.75 & 2.85 & 0.417 & 1.07 & 1.24 \\
Dec & 0.279 & 11.3 & 2.62 & 0.337 & 1.07 & 0.78 \\
\hline
\end{tabular}

Ramírez (2010). For the present application of the SW model to the two grassland sites, mean monthly values of all resistances and energy fluxes that are independent of LAI were calculated at each site using the values of corresponding grid cell over the period 1951-1980. These values were then used in combination with the LAI values specific to each month and model run to estimate the remainder of the variables in the SW model.

\section{Results and discussion}

We applied the solution methodology for the SDEM described in Sect. 3 to the CPER and R-5 sites over a range of values of peak green LAI. The given peak value was used to scale the monthly values in the LAI phenologies of Fig. 7. The results for root-zone volumetric soil moisture are shown in Fig. 8. For the CPER sandy-loam slope, August soil moisture falls between the critical and wilting point values for LAI values between and including 0.8 and 1.2. In compari-
Table 4. PRP Model Statistics for the R-5 Watershed.

\begin{tabular}{lllllll}
\hline Month & $\begin{array}{l}m_{\mathrm{tr}} \\
(\text { days })\end{array}$ & $\begin{array}{l}m_{\mathrm{tb}} \\
(\text { days })\end{array}$ & $\begin{array}{l}m_{i} \\
(\mathrm{~cm} / \text { days })\end{array}$ & $\begin{array}{l}m_{\mathrm{h}} \\
(\mathrm{cm})\end{array}$ & $k$ & $\begin{array}{l}E[P] \\
(\mathrm{cm})\end{array}$ \\
\hline Jan & 0.366 & 9.64 & 3.90 & 0.99 & 0.637 & 2.46 \\
Feb & 0.367 & 7.50 & 3.88 & 1.01 & 0.598 & 3.23 \\
Mar & 0.360 & 6.32 & 5.19 & 1.31 & 0.687 & 5.31 \\
Apr & 0.235 & 4.55 & 6.88 & 1.27 & 0.667 & 7.70 \\
May & 0.294 & 3.99 & 8.35 & 1.87 & 0.613 & 13.6 \\
Jun & 0.221 & 4.41 & 9.44 & 1.56 & 0.677 & 9.25 \\
Jul & 0.294 & 7.04 & 7.99 & 1.57 & 0.610 & 7.26 \\
Aug & 0.199 & 5.48 & 8.37 & 1.25 & 0.608 & 6.21 \\
Sep & 0.359 & 5.84 & 7.57 & 2.02 & 0.563 & 9.21 \\
Oct & 0.401 & 7.97 & 6.42 & 1.95 & 0.491 & 7.05 \\
Nov & 0.393 & 8.16 & 5.18 & 1.47 & 0.596 & 4.46 \\
Dec & 0.376 & 8.43 & 4.15 & 1.12 & 0.581 & 3.15 \\
\hline
\end{tabular}

son, Knight (1973) and Hazlett (1992) report observed values ranging from 0.4-0.6 for other locations at the CPER, with a strong dependency on grazing intensity. For the R-5 watershed, August soil moisture falls between the critical and wilting point values for peak green LAI values of 2.0, 2.5 and 3.0. In comparison, Luxmoore and Sharma (1980) and Ritchie et al. (1976) use values of 2.5 and 3.2, respectively, in their modeling studies. Therefore, for the ecological optimality hypothesis to reproduce precisely the observed LAI, the actual critical moisture content at the CPER would have to be about 0.03 higher than estimated, and about 0.02 lower at the R-5 watershed. The opposing directions of those adjustments is indication that we can attribute the differences between modeled and observed LAI to modeling and measurement error, as opposed to the optimality hypothesis being invalid.

We further examine the use of the critical matric potential as a means of estimating the peak in green LAI by comparison of observed with modeled soil moisture (Fig. 9). For the CPER, the modeled minimum in the root zone falls about 


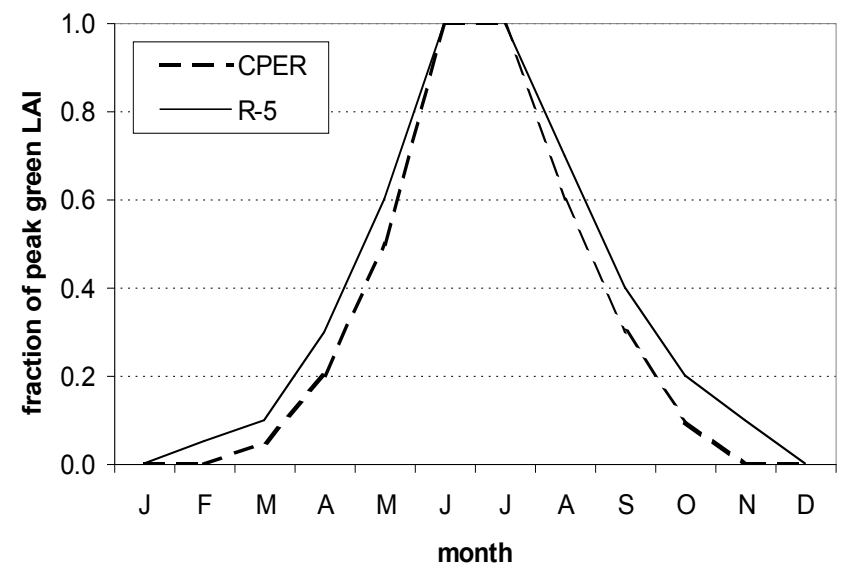

Fig. 7. Phenology of green LAI. The wider curve for the R-5 watershed is reflective of a longer growing season.

0.02 below the observed, while at R- 5 watershed it falls about 0.02 above the observed. These results are consistent with the hypothesized errors in the critical moisture content. Errors in either soil hydraulic parameters or the value of the critical matric potential would result in error in the critical moisture content. The difficulties with estimating the critical soil matric potential were discussed in Sect. 4.7. Errors in soil hydraulic parameters in general could explain the discrepancies between modeled and observed soil moisture. In particular, the greater modeled soil moisture in the recharge zone implies that the actual permeability of recharge-zone soil is substantially greater than that of the assumed hydraulic parameters. In contrast, the assumed soil hydraulic parameters in the recharge zone at the R-5 watershed provide a good estimate of the mean annual soil moisture content in that zone. The seasonality in the modeled rechargezone soil moisture that is absent in the observations could be damped out in the model results assuming a greater depth of the recharge zone. Thus a better a fit between modeled and observed soil moisture could be had by calibrating the identified parameters. However, use of the best a priori estimates is more informative in terms of testing the ecological optimality hypothesis, one of our major objectives, and the model's applicability to locations where soil moisture data are not available. At the end of this section, we examine the sensitivities of the model-determined peak in LAI and the water balance to variations in soil texture.

Figure 10 depicts the partitioning of the monthly water balance for both sites at the respective model-determined peak in green LAI. The negligibility of modeled surface runoff and groundwater recharge at the CPER is consistent with observations. The May peak in surface runoff at the R5 watershed also matches observations (USDA-ARS, 1983). However, the $0.9 \mathrm{~cm}$ of modeled annual mean surface runoff for R-5 watershed represents an underestimate of the measured value of $2.0 \mathrm{~cm}$ - not surprising given the large spatial (a) CPER

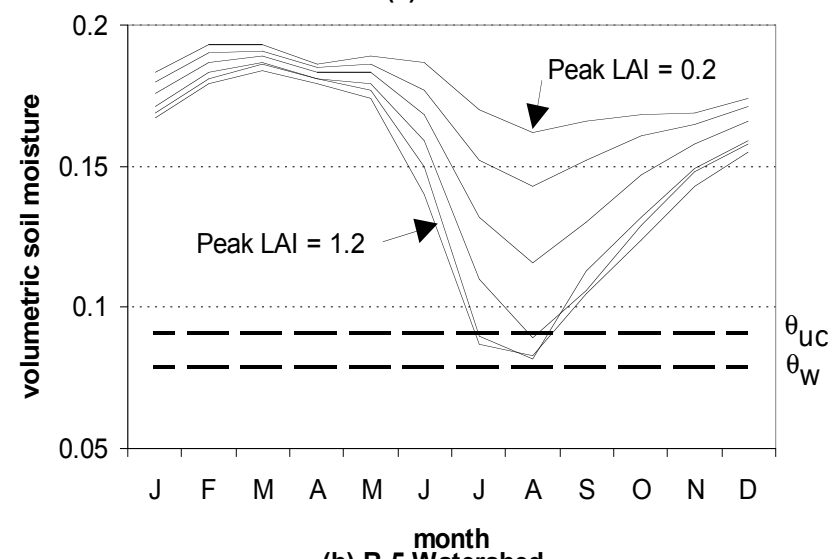

(b) R-5 Watershed

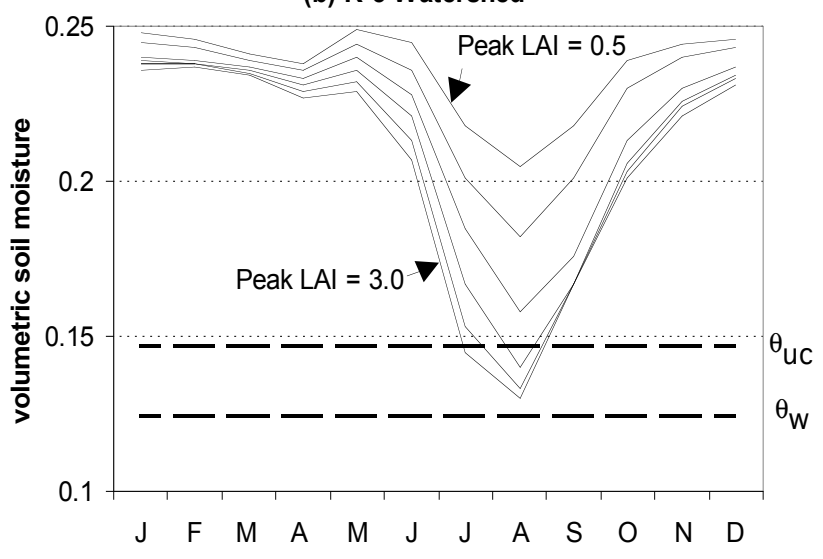

Fig. 8. Sensitivity of modeled root zone soil moisture to the peak in green LAI for: (a) the CPER sandy loam slope in LAI increments of 0.2 , and (b) the R-5 watershed in LAI increments of 0.5 .

variation in saturated hydraulic conductivity at the R-5 watershed (Loague and Gander, 1990). The ability of the model to capture runoff as the residual of evapotranspiration is explored further by Kochendorfer and Ramírez (2010).

For both sites, soil evaporation is the dominant flux leaving the soil outside of the growing season. During the growing season, it is at a peak in May and at a minimum in August. As the growing season progresses, soil evaporation decreases as the soil dries and LAI increases. From May to August at the CPER site, soil evaporation as a percentage of total evapotranspiration decreases from $67 \%$ to $6.4 \%$, with an average of $28 \%$. The modeled partitioning of evapotranspiration at the CPER site is consistent with the stable isotope study of Ferretti et al. (2003) and the energy-balance measurement and modeling study of Massman (1992), both conducted at the CPER. The latter study encompassed the entire growing season of 1989, during which soil evaporation was found to average $33 \%$ of total evapotranspiration. The former study shows a high degree of variability in partitioning over three growing seasons (1999-2001), with soil evaporation ranging from "nil to about 40\%." At 47\%, the May to August 
(a) CPER

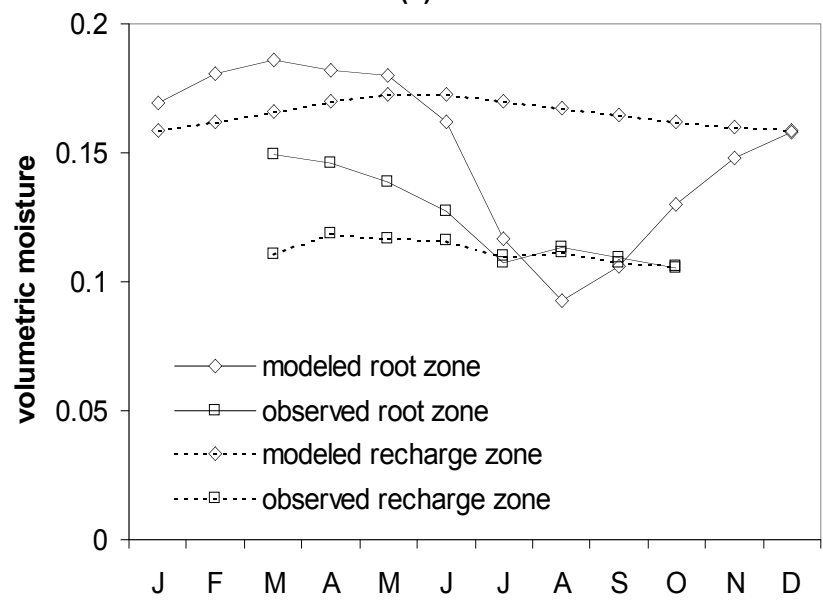

(b) R-5 Watershed

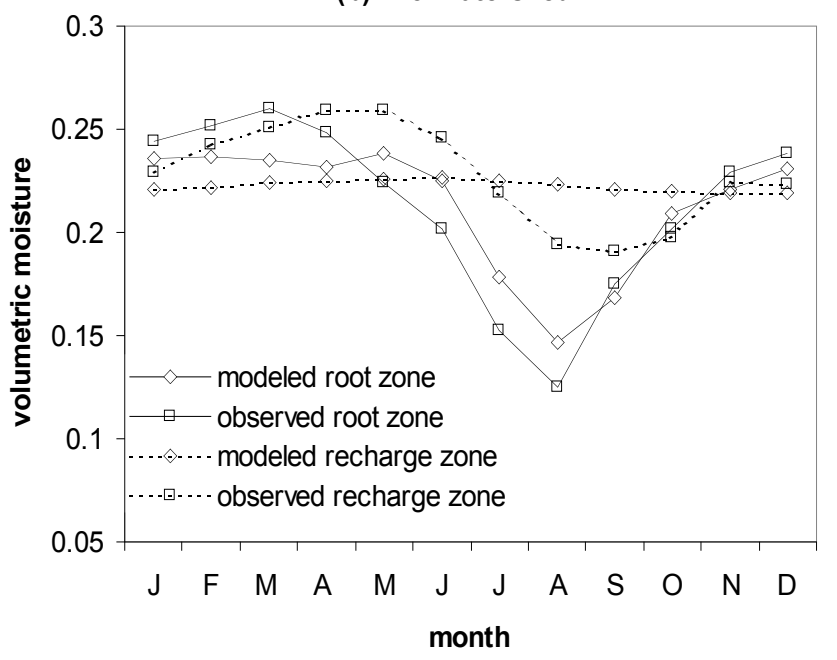

Fig. 9. Comparison of modeled and observed monthly mean soil moisture for: (a) the sandy-loam slope at the CPER, and (b) the R5 watershed. The observations for November-Febuary at the CPER are not plotted because of infrequent measurements (see Fig. 7a). The fact that observed spring recharge at the CPER is less than modeled is likely due to the first measurement being taken at a depth of $30 \mathrm{~cm}$. For a discussion of other discrepancies between modeled and observed soil moisture see Sect. 7.

percentage of evapotranspiration that is soil evaporation is somewhat higher for the R-5 watershed. In comparison to the CPER site, the greater percentage at the R-5 watershed suggests that the greater moisture content there more than offsets the lesser amount of shortwave energy reaching the soil surface (due to the greater LAI). These two opposing factors are explored further by Kochendorfer and Ramírez (2010).

Differences in soil texture may also play a role in the differences in evapotranspiration partitioning between the CPER site and the R-5 watershed. Using soil hydraulic parameters for the five soil textures in Table 2 we modeled the optimal peak in LAI and the associated water balance. For (a) CPER

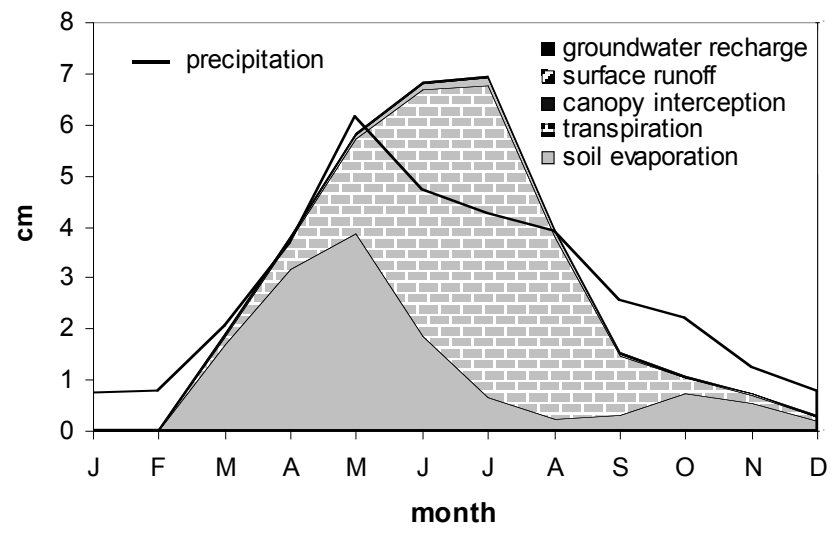

(b) R-5 Watershed

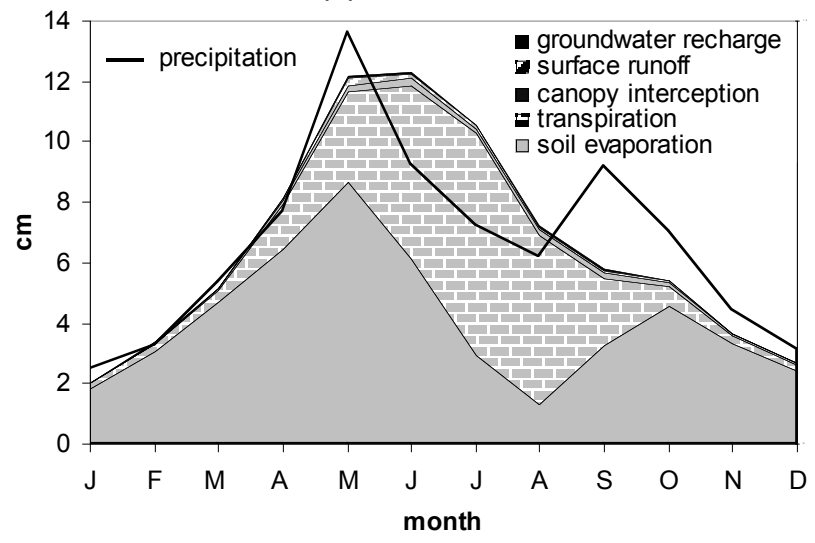

Fig. 10. Components of the modeled monthly mean water balance for: (a) the CPER silt-loam slope with a peak green LAI of 0.74, and (b) the R-5 watershed with a peak green LAI of 1.8. All losses are plotted on top of each other such that when their sum is greater than precipitation, soil and/or snow storages are being depleted, and when their sum is less than precipitation, the storages are being recharged.

both the CPER and R-5 watershed, the largest LAI (Fig. 11) and smallest percentage of evapotranspiration that is soil evaporation (Fig. 12) were achieved with sand, the most permeable of the five soil textures. These results are consistent with the inverse texture effect discussed in Sect. 1. While one expects the inverse texture effect to be in force in the semi-arid climate of the CPER, it may not be the case in the semi-humid climate of the R-5 watershed. Using linear regression analysis of the relationship between water holding capacity, grass ANPP and average annual precipitation, Sala et al. (1988) determine that the inverse texture effect predominates in the Great Plains where annual precipitation is below $37 \mathrm{~cm}$. Epstein et al. (1997b) use the same USDA rangeland yield data at a higher resolution in a linear regression study with the independent variables as mean annual temperature, mean annual precipitation, and soil texture in the form of percentages of sand and clay. They find that at $80 \mathrm{~cm}$ 


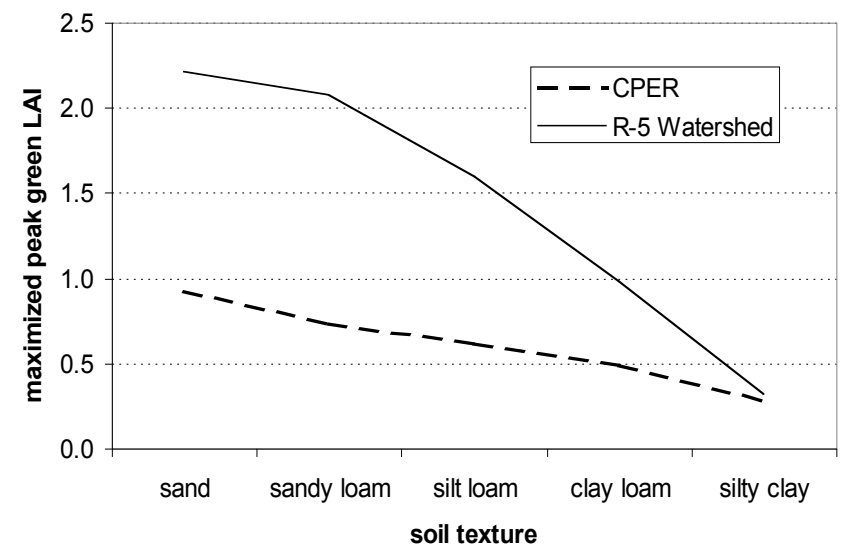

Fig. 11. Sensitivity of model-determined green LAI to variations in soil texture for: (a) the CPER, and (b) the R-5 watershed.

of precipitation ANPP switches from increasing with sand content and decreasing with clay content to the reverse dependencies. The sensitivity of model-determined LAI for the CPER to changes in the percentages of sand and clay (see Table 2 and Fig. 11) are consistent with the regression coefficients listed by Epstein et al. (1997b) for the $30-50 \mathrm{~cm}$ interval of annual precipitation. In contrast, the R-5 watershed is just at the $80-\mathrm{cm}$ crossover point, and thus the sensitivity of model-determined LAI to soil texture at the R-5 watershed is much greater than the sensitivity of ANPP observed by Epstein et al. (1997b) for the corresponding precipitation interval. In general, as one moves away from principally water-limited systems to principally light- and nutrientlimited systems, the LAI-optimization hypothesis used in the SDEM becomes less applicable. In particular, the ability of clay to adsorb nutrients offsets its low permeability to water.

\section{Summary and conclusions}

A monthly, two-soil-layer version of the Eagleson statisticaldynamical water balance model has been developed and coined the Statistical-Dynamical Ecohydrology Model (SDEM). Additional enhancements to the model include snow and frozen soil, and a more physically based representation of vegetation. The latter was achieved in part by coupling the water balance model to the ShuttleworthWallace (SW) evapotranspiration model. In the SW model, LAI is the principal vegetation property that determines the partitioning of energy between the vegetation canopy and the soil surface. Results presented demonstrate the ability of the SDEM to capture well the seasonal dynamics of the local-scale soil-water balance.

The new coupled SDEM-SW model allows examination of an ecological optimality hypothesis of an "optimal" peak green LAI in water-limited systems, in which soil moisture in the mean monthly water balance is drawn down to some (a) CPER

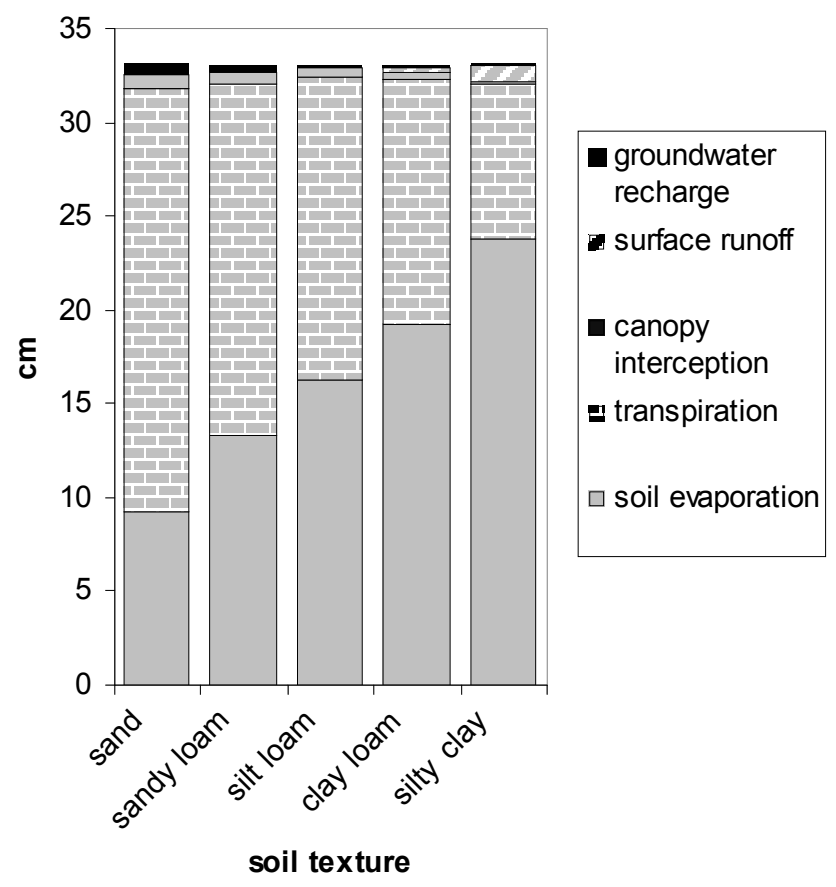

(b) R-5 Watershed

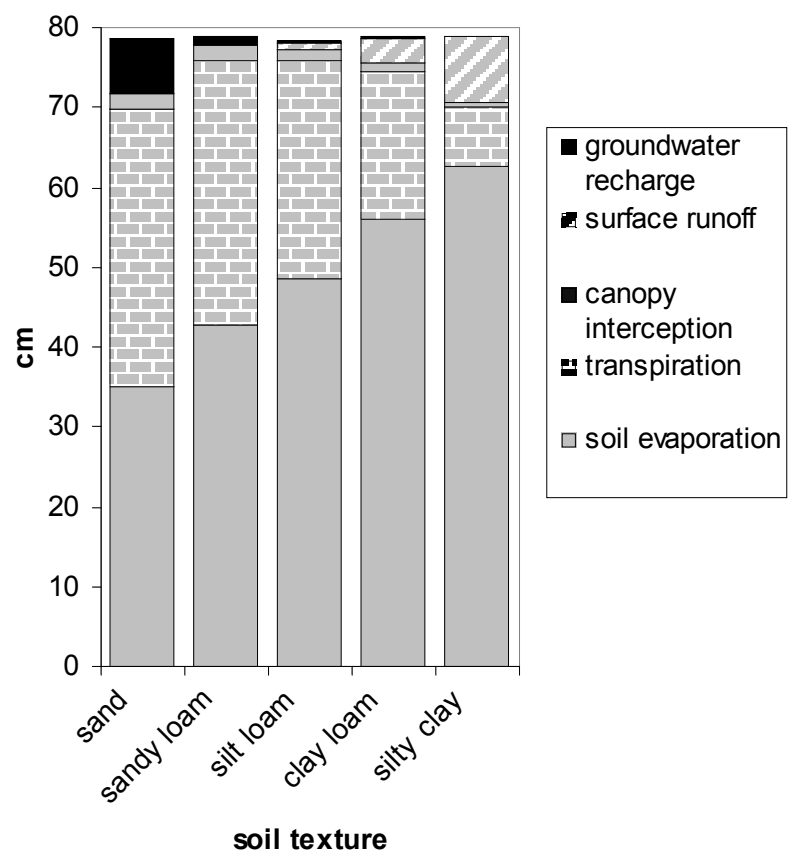

Fig. 12. Sensitivity of the components of the annual water balance to variations in soil texture for: (a) the CPER, and (b) the R-5 watershed.

minimum in the later part of the growing season. Application of the SDEM to two native grassland sites in the US Great Plains, suggested that the soil-moisture minimum is somewhat above the wilting point matric potential and that the soil matric potential at which stomatal closure is initiated 
- termed the critical matric potential - may approximate well the minimum. From an ecological optimality standpoint, this may represent a balance between the evolutionary imperative to maximize fecundity and the need to reduce the risk of premature leaf abscission. On the other hand, the data uncertainties are great enough and the difference between the wilting point and critical matric potentials small enough that it could be argued that there is no optimal use of soil water but rather a "tragedy of the commons" in which competition between individuals results in complete exhaustion of available soil moisture. Most likely, plant water use is determined by some combination of individual optimal use and maximum use via competition (e.g., Zea-Cabrera et al., 2006). We have begun exploring the competition between plants with the SDEM by inclusion of multiple root sinks and associated potential rates of transpiration.

Another enhancement to the model being explored is inclusion of inter-storm water stress with the framework of Sect. 4.7. The role of inter-storm water-stress has been extensively studied by others using the statistical-dynamical water balance model of Rodriguez-Iturbe et al. (1999). In particular, Laio et al. (2001) argue that the lesser time spent in interstorm water stress for sandier soils explains the inverse texture effect at the CPER. We on the other hand have demonstrated the inverse texture effect with a model that accounts for only seasonal water stress. We believe that the SDEM captures the inverse texture effect because it accurately partitions evapotranspiration into transpiration and evaporation from the soil surface - that partitioning is not done in the model of Rodriguez-Iturbe et al. Namely, it produces the increase in soil evaporation with decreasing soil permeability that Noy-Meir (1973) hypothesized to be the cause of the inverse texture effect.

Acknowledgements. This work was partially supported by the National Institute for Global Environmental Change through the US Department of Energy (Cooperative Agreement DE-FC0390ER61010). Some of this work was performed while the second author was on sabbatical leave at the Swiss Federal Institute of Technology (ETH-Z) whose support is gratefully acknowledged. We sincerely acknowledge the review comments of the editor and two anonymous reviewers.

Edited by: S. Manfreda

\section{Appendix A}

\section{Nomenclature of symbols}

\begin{tabular}{|c|c|c|}
\hline \multicolumn{3}{|c|}{ Nomenclature of latin symbols } \\
\hline Symbol & Description & Units \\
\hline$A$ & $\begin{array}{l}\text { available energy over the entire } \\
\text { land surface }\end{array}$ & $\mathrm{Wm}^{-2}$ \\
\hline$A_{\mathrm{s}}$ & $\begin{array}{l}\text { available energy at the soil } \\
\text { surface }\end{array}$ & $\mathrm{Wm}^{-2}$ \\
\hline$A_{\mathrm{o}}$ & $\begin{array}{l}\text { Asymptote of infiltration } \\
\text { capacity curve }\end{array}$ & $\mathrm{cm} /$ day \\
\hline$b$ & $\begin{array}{l}\text { sensitivity of stomatal resis- } \\
\text { tance to irradiance }\end{array}$ & $\mathrm{sm}^{-1} \mathrm{Wm}^{-2}$ \\
\hline$c$ & pore disconnectedness index & dimensionless \\
\hline$c_{\mathrm{p}}$ & $\begin{array}{l}\text { specific heat at constant } \\
\text { pressure }\end{array}$ & $\mathrm{Jkg}^{-1 \circ} \mathrm{C}^{-1}$ \\
\hline$C$ & $\begin{array}{l}\text { product of the heat capacity and } \\
\text { the thermal conductivity of the } \\
\text { soil }\end{array}$ & $\mathrm{W}^{2} \mathrm{~m}^{-4 \circ} \mathrm{C}^{-2}$ day \\
\hline$C_{\mathrm{fs}}$ & $\begin{array}{l}\text { frozen-soil correction factor for } \\
\text { hydraulic conductivity }\end{array}$ & dimensionless \\
\hline$d$ & $\begin{array}{l}\text { zero plane displacement of the } \\
\text { closed canopy }\end{array}$ & $\mathrm{m}$ \\
\hline$D$ & $\begin{array}{l}\text { vapor pressure deficit at the ref- } \\
\text { erence height }\end{array}$ & $\mathrm{mb}$ \\
\hline$D_{\mathrm{e}}$ & exfiltration diffusivity & $\mathrm{cm}^{2} /$ day \\
\hline$D_{\mathrm{i}}$ & infiltration diffusivity & $\mathrm{cm}^{2} /$ day \\
\hline$D_{\mathrm{o}}$ & $\begin{array}{l}\text { vapor pressure deficit at height } \\
\text { of mean canopy flow }\end{array}$ & $\mathrm{mb}$ \\
\hline$e_{\mathrm{hv}}$ & $\begin{array}{l}\text { mean rate of evaporation from } \\
\text { canopy interception }\end{array}$ & $\mathrm{cm} /$ day \\
\hline$e_{\mathrm{ps}}$ & $\begin{array}{l}\text { mean rate of potential evapora- } \\
\text { tion from the soil surface }\end{array}$ & $\mathrm{cm} /$ day \\
\hline$e_{\mathrm{pv}}$ & $\begin{array}{l}\text { mean rate of potential } \\
\text { transpiration }\end{array}$ & $\mathrm{cm} /$ day \\
\hline $\begin{array}{l}e_{\mathrm{v}} \\
\operatorname{erfc}[\sim]\end{array}$ & $\begin{array}{l}\text { mean rate of transpiration } \\
\text { complimentary error function }\end{array}$ & $\begin{array}{l}\mathrm{cm} / \text { day } \\
\text { dimensionless }\end{array}$ \\
\hline$E[\sim]$ & expected value & \\
\hline$E_{\mathrm{hv}}$ & $\begin{array}{l}\text { evaporation from canopy } \\
\text { interception }\end{array}$ & $\mathrm{cm}$ \\
\hline$E_{\mathrm{S}}$ & $\begin{array}{l}\text { evaporation from the soil } \\
\text { surface }\end{array}$ & $\mathrm{cm}$ \\
\hline$E_{\mathrm{T}}$ & $\begin{array}{l}\text { total evapotranspiration from } \\
\text { soil }\end{array}$ & $\mathrm{cm}$ \\
\hline $\begin{array}{l}E_{\mathrm{V}} \\
f_{\mathrm{c}}\end{array}$ & $\begin{array}{l}\text { transpiration from vegetation } \\
\text { factor for the conversion of } \\
\mathrm{mm} / \mathrm{s} \text { to } \mathrm{cm} / \text { day }(=8640)\end{array}$ & $\mathrm{cm}$ \\
\hline$f_{\mathrm{i}}(t)$ & $\begin{array}{l}\text { infiltration capacity as a } \\
\text { function of time }\end{array}$ & $\mathrm{cm} /$ day \\
\hline$f_{\mathrm{e}}(t)$ & $\begin{array}{l}\text { exfiltration capacity as a } \\
\text { function of time }\end{array}$ & $\mathrm{cm} /$ day \\
\hline$f_{\mathrm{p}}$ & $\begin{array}{l}\text { ratio of persistent non- } \\
\text { transpiring LAI to peak green } \\
\text { LAI }\end{array}$ & dimensionless \\
\hline$f_{\mathrm{s}}$ & $\begin{array}{l}\text { fraction of precipitation which } \\
\text { is snow }\end{array}$ & dimensionless \\
\hline
\end{tabular}




\begin{tabular}{|c|c|c|}
\hline \multicolumn{3}{|c|}{ Nomenclature of latin symbols cont. } \\
\hline Symbol & Description & Units \\
\hline$h$ & storm depth & $\mathrm{cm}$ \\
\hline$h_{\mathrm{c}}$ & canopy height & $\mathrm{m}$ \\
\hline$h_{\mathrm{v}}$ & $\begin{array}{l}\text { interception capacity of the } \\
\text { vegetation canopy }\end{array}$ & $\mathrm{cm}$ \\
\hline$i$ & storm intensity & $\mathrm{cm} /$ day \\
\hline$i_{\mathrm{W}}$ & intensity of snow-melt pulse & $\mathrm{cm} /$ day \\
\hline$I$ & Infiltration & $\mathrm{cm}$ \\
\hline$J$ & $\begin{array}{l}\text { Julian day of the middle } \\
\text { of the month }\end{array}$ & number \\
\hline$k$ & von Karmans constant & dimensionless \\
\hline$k_{\mathrm{V}}$ & transpiration coefficient & dimensionless \\
\hline$K(s)$ & soil hydraulic conductivity & $\mathrm{cm} /$ day \\
\hline$K_{\mathrm{S}}$ & saturated hydraulic conductivity & $\mathrm{cm} /$ day \\
\hline$L_{\mathrm{D}}$ & $\begin{array}{l}\text { leaf area index of standing dead } \\
\text { and other non-transpiring plant } \\
\text { material }\end{array}$ & dimensionless \\
\hline$L_{\mathrm{G}}$ & $\begin{array}{l}\text { leaf area index of transpiring } \\
\text { (green) leaves }\end{array}$ & dimensionless \\
\hline$L_{\mathrm{T}}$ & total leaf area index & dimensionless \\
\hline$L_{\mathrm{n}}$ & net outgoing longwave radiation & $\mathrm{Wm}^{-2}$ \\
\hline$m$ & pore size distribution index & dimensionless \\
\hline$m_{\mathrm{h}}$ & mean storm depth & $\mathrm{cm}$ \\
\hline$m_{\mathrm{i}}$ & mean storm intensity & $\mathrm{cm} /$ day \\
\hline$m_{\mathrm{tb}}$ & $\begin{array}{l}\text { mean duration of interstorm } \\
\text { periods }\end{array}$ & days \\
\hline$m_{\text {th }}$ & $\begin{array}{l}\text { mean time for canopy } \\
\text { interception to evaporate }\end{array}$ & days \\
\hline$m_{\mathrm{tr}}$ & mean storm duration & days \\
\hline$m_{i}$ & mean number of storms & number \\
\hline$M$ & vegetation density & dimensionless \\
\hline$n$ & effective porosity & dimensionless \\
\hline$n_{\mathrm{e}}$ & $\begin{array}{l}\text { eddy diffusion decay constant } \\
\text { for the closed canopy }\end{array}$ & dimensionless \\
\hline$n_{\mathrm{t}}$ & total porosity & dimensionless \\
\hline$n_{\mathrm{w}}$ & wind speed decay constant & dimensionless \\
\hline$P$ & precipitation & $\mathrm{cm}$ \\
\hline$Q$ & vertical flow through the soil & $\mathrm{cm}$ \\
\hline$r_{\mathrm{aa}}$ & $\begin{array}{l}\text { aerodynamic resistance } \\
\text { between the height of mean } \\
\text { canopy flow }\end{array}$ & \\
\hline & and the reference height & $\mathrm{sm}^{-1}$ \\
\hline$r_{\mathrm{ac}}$ & $\begin{array}{l}\text { bulk leaf-boundary-layer } \\
\text { resistance of the } \\
\text { canopy }\end{array}$ & $\mathrm{sm}^{-1}$ \\
\hline$r_{\text {as }}$ & $\begin{array}{l}\text { aerodynamic resistance } \\
\text { between the soil and mean } \\
\text { canopy flow }\end{array}$ & $\mathrm{sm}^{-1}$ \\
\hline$r_{\mathrm{sc}}$ & $\begin{array}{l}\text { bulk stomatal resistance of the } \\
\text { unstressed canopy }\end{array}$ & $\mathrm{sm}^{-1}$ \\
\hline$r_{\mathrm{s}}$ & stomatal resistance & $\mathrm{sm}^{-1}$ \\
\hline$r_{\mathrm{smin}}$ & minimum stomatal resistance & $\mathrm{sm}^{-1}$ \\
\hline$r_{\mathrm{ss}}$ & $\begin{array}{l}\text { resistance at the soil surface } \\
\text { during stage-one evaporation }\end{array}$ & $\mathrm{sm}^{-1}$ \\
\hline$R_{\mathrm{g}}$ & recharge to groundwater & $\mathrm{cm}$ \\
\hline$R_{\mathrm{n}}$ & $\begin{array}{l}\text { net radiation over the entire land } \\
\text { surface }\end{array}$ & $\mathrm{Wm}^{-2}$ \\
\hline
\end{tabular}

\begin{tabular}{|c|c|c|}
\hline \multicolumn{3}{|c|}{ Nomenclature of latin symbols cont. } \\
\hline Symbol & Description & Units \\
\hline$R_{\mathrm{ns}}$ & net radiation at the soil surface & $\mathrm{Wm}^{-2}$ \\
\hline$R_{\mathrm{S}}^{*}$ & rainfall excess & $\mathrm{cm}$ \\
\hline$R_{\mathrm{S}}$ & $\begin{array}{l}\text { infiltration-excess } \\
\text { surface runoff }\end{array}$ & $\mathrm{cm}$ \\
\hline$R_{\mathrm{V}}$ & $\begin{array}{l}\text { resistance to water flow in the } \\
\text { vegetation }\end{array}$ & days \\
\hline$R_{\mathrm{W}}$ & surface runoff from snow melt & $\mathrm{cm}$ \\
\hline$s$ & relative soil saturation & dimensionless \\
\hline$s_{33}$ & $s$ at $33 \mathrm{kPa}$ & dimensionless \\
\hline$s_{\mathrm{O}}$ & $\begin{array}{l}\text { value of s that closes the mean } \\
\text { annual water balance }\end{array}$ & dimensionless \\
\hline$s_{\mathrm{p}}$ & $\begin{array}{l}\text { mean s over the post-storm } \\
\text { wetting front }\end{array}$ & dimensionless \\
\hline$s_{\mathrm{W}}$ & $\begin{array}{l}\text { relative soil saturation at the } \\
\text { permanent wilting point }\end{array}$ & dimensionless \\
\hline$S$ & $\begin{array}{l}\text { water equivalent of the snow } \\
\text { pack }\end{array}$ & $\mathrm{cm}$ \\
\hline$S_{\mathrm{e}}$ & exfiltration sorptivity & $\mathrm{cm} /$ day $^{1 / 2}$ \\
\hline$S_{\mathrm{i}}$ & infiltration sorptivity & $\mathrm{cm} /$ day $^{1 / 2}$ \\
\hline$T$ & mean monthly air temperature & ${ }^{\circ} \mathrm{C}$ \\
\hline$T_{\max }$ & $\begin{array}{l}\text { annual maximum in monthly } \\
\text { mean air temperature }\end{array}$ & ${ }^{\circ} \mathrm{C}$ \\
\hline$T_{\min }$ & $\begin{array}{l}\text { annual minimum in monthly } \\
\text { mean air temperature }\end{array}$ & $7^{\circ} \mathrm{C}$ \\
\hline$t$ & Time & days \\
\hline$t_{\mathrm{b}}$ & time between storms & days \\
\hline$t_{\mathrm{d}}$ & length of daylight & days \\
\hline$t_{\mathrm{e}}$ & $\begin{array}{l}\text { time to effective end of evapo- } \\
\text { ration from the soil surface }\end{array}$ & days \\
\hline$t_{\mathrm{p}}$ & ponding time & days \\
\hline$t_{\mathrm{s}}$ & $\begin{array}{l}\text { time shift of the infiltration and } \\
\text { exfiltration capacity functions }\end{array}$ & days \\
\hline$t_{\mathrm{r}}$ & storm duration & days \\
\hline$t_{\mathrm{rw}}$ & duration of snow-melt pulse & $\mathrm{cm} /$ day \\
\hline$u$ & $\begin{array}{l}\text { wind speed at the reference } \\
\text { height }\end{array}$ & $\mathrm{m} / \mathrm{s}$ \\
\hline$u_{\mathrm{c}}$ & wind speed at the canopy height & $\mathrm{m} / \mathrm{s}$ \\
\hline$W$ & Water equivalent of snow melt & $\mathrm{cm}$ \\
\hline$w$ & $\begin{array}{l}\text { weighting factor for terms of the } \\
\text { infiltration capacity function }\end{array}$ & dimensionless \\
\hline$w_{1}$ & average leaf width & $\mathrm{m}$ \\
\hline$x_{\mathrm{r}}$ & $\begin{array}{l}\text { reference height above the } \\
\text { canopy for meteorological } \\
\text { measurements }\end{array}$ & $\mathrm{m}$ \\
\hline$z$ & thickness of soil layer & $\mathrm{cm}$ \\
\hline$z_{\mathrm{p}}$ & $\begin{array}{l}\text { mean penetration depth for the } \\
\text { wetting front }\end{array}$ & $\mathrm{cm}$ \\
\hline$z_{\mathrm{o}}$ & $\begin{array}{l}\text { roughness length of the closed } \\
\text { canopy }\end{array}$ & $\mathrm{m}$ \\
\hline$z_{\mathrm{os}}$ & $\begin{array}{l}\text { the roughness length of the soil } \\
\text { surface }\end{array}$ & $\mathrm{m}$ \\
\hline
\end{tabular}




\begin{tabular}{|c|c|c|}
\hline \multicolumn{3}{|c|}{ Nomenclature of greek symbols } \\
\hline Symbol & Description & Units \\
\hline$\alpha$ & $\begin{array}{l}\text { reflectance of the surface the } \\
\text { shortwave radiation }\end{array}$ & dimensionless \\
\hline$\beta$ & root density decay constant & dimensionless \\
\hline$\gamma$ & psychrometric constant & $\mathrm{mb}^{\circ} \mathrm{C}^{-1}$ \\
\hline$\gamma[\sim]$ & incomplete gamma function & dimensionless \\
\hline$\Gamma[\sim]$ & gamma function & \\
\hline$\Delta$ & $\begin{array}{l}\text { gradient of saturated vapor pres- } \\
\text { sure deficit with temperature }\end{array}$ & $\mathrm{mb}^{\circ} \mathrm{C}^{-1}$ \\
\hline$\theta$ & $\begin{array}{l}\text { effective volumetric soil water } \\
\text { content }\end{array}$ & dimensionless \\
\hline$\theta_{\mathrm{i}}$ & $\begin{array}{l}\text { initial volumetric soil water } \\
\text { content }\end{array}$ & dimensionless \\
\hline$\theta_{\mathrm{o}}$ & $\begin{array}{l}\text { volumetric soil water content at } \\
\text { the soil surface }\end{array}$ & dimensionless \\
\hline$\theta_{\mathrm{r}}$ & $\begin{array}{l}\text { residual volumetric soil water } \\
\text { content }\end{array}$ & dimensionless \\
\hline$\theta_{\mathrm{t}}$ & $\begin{array}{l}\text { total volumetric soil water } \\
\text { content }\end{array}$ & dimensionless \\
\hline$\kappa$ & $\begin{array}{l}\text { parameter of the gamma } \\
\text { distribution of } h\end{array}$ & dimensionless \\
\hline$\lambda$ & latent heat of vaporization & $\mathrm{J} / \mathrm{kg}$ \\
\hline$\mu$ & Beers law extinction coefficient & dimensionless \\
\hline$\rho$ & density of air & $\mathrm{kgm}^{-3}$ \\
\hline$\sigma$ & capillary infiltration parameter & dimensionless \\
\hline$\tau$ & length of the month & days \\
\hline$\phi_{\mathrm{i}}(\mathrm{s}, \mathrm{m})$ & effective infiltration diffusivity & dimensionless \\
\hline$\psi(\mathrm{s})$ & soil matric potential & $\mathrm{cm}$ \\
\hline$\psi_{\mathrm{lc}}$ & critical leaf-water potential & $\mathrm{cm}$ \\
\hline$\psi_{\mathrm{s}}$ & bubbling soil matric potential & $\mathrm{cm}$ \\
\hline$\psi_{\mathrm{uc}}$ & $\begin{array}{l}\text { critical root-zone soil matric } \\
\text { potential }\end{array}$ & $\mathrm{cm}$ \\
\hline
\end{tabular}

\begin{tabular}{|c|c|}
\hline \multicolumn{2}{|c|}{ Nomenclature of recurring subscripts } \\
\hline Symbol & Description \\
\hline$a$ & $\begin{array}{l}\text { air in or above the vegetation } \\
\text { canopy }\end{array}$ \\
\hline$c$ & $\begin{array}{l}\text { vegetation canopy or critical } \\
\text { level }\end{array}$ \\
\hline$d$ & deep/recharge zone of soil \\
\hline$i$ & $\begin{array}{l}i \text { month of the year or } \\
\text { infiltration }\end{array}$ \\
\hline$j$ & $j$ storm/interstorm period \\
\hline$p$ & peak, persistent or post-storm \\
\hline$s$ & $\begin{array}{l}\text { soil surface, saturated or plant } \\
\text { stomata }\end{array}$ \\
\hline$u$ & upper/root zone of soil \\
\hline$v$ & vegetation \\
\hline$A$ & annual \\
\hline$T$ & total \\
\hline
\end{tabular}

\section{References}

Bond, J. J. and Willis, W. O.: Soil water evaporation: surface residue rate and placement effects, Soil Sci. Soc. Am. Pro., 33, 445-448, 1969.

Braud, I., Dantasantonino, A. C., Vauclin, M., Thony, J. L., and Ruelle, P.: A Simple Soil-Plant-Atmosphere Transfer (SiSPAT) model: Development and field verification, J. Hydrol., 166(3-4), 213-250, 1995.

Brooks, R. H. and Corey, A. T.: Properties of porous media affecting fluid flow, Journal of Irrigation Drainage Division of American Society of Civil Engineers, IR2, 61-88, 1966.

Brutsaert, W. and Chen, D.: Desorption and the two stages of drying of natural tallgrass prairie, Water Resour. Res., 31(5), 305-1313, 1995.

Camillo, P. J. and Gurney, R. J.: A resistance parameter for bare-soil evaporation models, Soil Sci., 141, 95-105, 1986.

Carslaw, H. S. and Jaeger, J. C.: Conduction of Heat in Solids, Oxford University Press, New York, 510 pp., 1959.

Carter, T. R., Hulme, M., and Viner, D.: Representing uncertainty in climate change scenarios and impact studies. Report no. 1, ECLAT-2 Workshop. Climate Research Unit, University of East Anglia, Norwich, UK, 125 pp., 1999.

Choudhury, B. J. and Monteith, J. L.: A four-layer model for the heat budget of homogeneous land surfaces, Q. J. Roy. Meteor. Soc., 114, 373-398, 1988.

Cosby, B. J., Hornberger, G. M., Clapp, R. B., and Ginn, T. R.: A statistical exploration of the relationships of soil moisture characteristics to the physical properties of soils, Water Resour. Res., 20(6), 682-690, 1984.

Cowan, I. R.: Transport of water in the soil-plant-atmosphere system, J. Appl. Ecol., 2, 221-239, 1965.

Dickinson, R. E., Henderson-Sellers, A., and Kennedy, P. J.: Biosphere-Atmosphere Transfer Scheme (BATS) Version 1e as Coupled to the NCAR Community Climate Model, University Corporation for Atmospheric Research, Boulder, CO., 69 pp., 1993.

Eagleson, P. S.: Climate, soil, and vegetation: 1. Introduction to water balance dynamics, Water Resour. Res., 14(5), 705-712, 1978a.

Eagleson, P. S.: Climate, soil, and vegetation: 2. The distribution of annual precipitation derived from observed sequences, Water Resour. Res., 14(5), 713-721, 1978 b.

Eagleson, P. S.: Climate, soil, and vegetation: 3. A simplified model of soil moisture movement in the liquid phase, Water Resour. Res., 14(5), 722-730, 1978c.

Eagleson, P. S.: Climate, soil, and vegetation: 4 . The expected value of annual evapotranspiration, Water Resour. Res., 14(5), 731739, 1978d.

Eagleson, P. S.: Climate, soil, and vegetation: 5. A derived distribution of storm surface runoff, Water Resour. Res., 14(5), 740-748, 1978e.

Eagleson, P. S.: Climate, soil, and vegetation: 6. Dynamics of the annual water balance, Water Resour. Res., 14(5), 749-764, $1978 f$.

Eagleson, P. S.: Climate, soil, and vegetation: 7. A derived distribution of annual water yield, Water Resour. Res., 14(5), 765-776, $1978 \mathrm{~g}$.

Eagleson, P. S.: Ecological Optimality in water-limited natural soil-vegetation systems 1 . Theory and hypothesis, Water Resour. 
Res., 18, 325-340, 1982.

Eagleson, P. S.: Ecohydrology: Darwinian expression of vegetation form and function. Cambridge University Press, Cambridge, UK, 443 pp., 2002.

Eagleson, P. S. and Tellers, T. E.: Ecological Optimality in waterlimited natural soil-vegetation systems 2 . Tests and applications, Water Resour. Res., 18, 341-354., 1982.

Entekhabi, D. and Eagleson, P. S.: Landsurface hydrology parameterization for atmospheric general circulation models including subgrid scale spatial variability, J. Clim., 2, 816-831, 1989.

Epstein, H. E., Lauenroth, W. K., and Burke, I. C.: Effects of temperature and soil texture on ANPP in the US great plains, Ecology, 78, 2628-2631, 1997b.

Federer, C. A.: A soil-plant-atmosphere model for transpiration and availability of soil water, Water Resour. Res., 15, 555-562, 1979.

Ferretti, D. F., Pendall, E., Morgan, J. A., Nelson, J. A., LeCain, D., and Mosier, A. R.: Partitioning evapotranspiration fluxes from a Colorado grassland using stable isotopes: Seasonal variations and ecosystem implications of elevated atmospheric $\mathrm{CO}_{2}$, Plant. Soil, 254, 291-303, 2003.

Gardner, W. R.: Dynamic aspects of water availability to plants, Soil Sci., 89, 63-73, 1960.

Guswa, A. J., Celia, M. A., and Rodriguez-Iturbe, I.: Models of soil moisture dynamics in ecohydrology: A comparative study, Water Resour. Res., 38, 1166-1181, 2002.

Hatton, T. J., Salvucci, G. D., and Wu, H. I.: Eagleson's optimality theory of an ecohydrological equilibrium: quo vadis?, Ecology, 11, 665-674, 1997.

Hazlett, D.: Leaf area development of four plant communities in the Colorado steppe, The American Midland Naturalist, 127, 276289, 1992 .

Jackson, R. B., Canadell, J., Ehleringer, J. R., Mooney, H. A., Sala, O. E., and Schulze, E. D.: A global analysis of root distributions for terrestrial biomes, Oecologia, 108, 389-411, 1996.

Jones, R. N.: Managing uncertainty in climate change projections - issues for impact assessment, Climatic Change, 45, 403-419, 2000.

Kergoat, L.: A model for hydrological equilibrium of leaf area index on a global scale, J. Hydrol., 213(1-4), 268-286, 1998.

Kerkhoff, A. J., Martens, S. N., and Milne, B. T.: An ecological evaluation of Eagleson's optimality hypotheses, Funct. Ecol., 18, 404-413, 2004.

Kittel, T. G. F., Rosenbloom, N. A., Painter, T. H., Schimel, D. S., and Participants, V. M.: The VEMAP integrated database for modeling United States ecosystem/vegetation sensitivity to climate change, J. Biogeogr., 22(4-5), 857-862, 1995.

Knight, D.: Leaf area dynamics of a shortgrass prairie in Colorado, Ecology, 54, 891-896, 1973.

Kochendorfer, J. P.: A monthly, two-soil-layer statitisticaldynamical water balance model for ecohydrologically focused climate impact assessment, Ph.D. dissertation, Department of Civil Engineering, Colorado State University, Fort Collins, CO, 211 pp., 2005.

Kochendorfer, J. P. and Ramírez, J. A.: Ecohydrological controls on vegetation density and evapotranspiration partitioning across the climatic gradients of the central United States, Hydrol. Earth Syst. Sci., 14, 2121-2139, doi:10.5194/hess-14-21212010, 2010.

Lafleur, P. M. and Rouse, W. R.: Application of an energy combi- nation model for evaporation from sparse canopies, Agr. Forest. Meteorol., 49, 135-153., 1990.

Laio, F., Porporato, A., Fernandez-Illescas, C. P., and RodriguezIturbe, I.: Plants in water-controlled ecosystems: active role in hydrologic processes and response to water stress IV. Discussion of real cases, Adv. Water Resour., 24, 745-762, 2001.

Lee, C. A. and Lauenroth, W. K.: Spatial distributions of grass and shrub root systems in the shortgrass steppe American Midland Naturalist, 132, 117-123, 1994.

Loague, K.: Soil water content a R-5. Part 1. Spatial and temporal variability, J. Hydrol., 139, 233-251, 1992.

Loague, K. and Gander, G. A.: R-5 Revisited: 1. Spatial variability of infiltration on a small rangeland catchment, Water Resour. Res., 26(5), 957-971, 1990.

Luxmoore, R. J. and Sharma, M. L.: Runoff responses to soil heterogeneity: Experimental and simulation comparisons for two contrasting watersheds, Water Resour. Res., 16, 675-684, 1980.

Massman, W. J.: A Surface-Energy Balance Method for Partitioning Evapotranspiration data into Plant and Soil components for a surface with Partial Canopy Cover, Water Resour. Res., 28(6), 1723-1732, 1992.

Milly, P. C. D.: Climate, soil water storage, and the average annual water balance, Water Resour. Res., 30(7), 2143-2156, 1994.

Monteith, J. L.: Evaporation and the environment, Symposia of the Society for Experimental Biology, 19, 205-234, 1965.

Neilson, R. P.: A model for predicting continental-scale vegetation distribution and water balance, Ecol. Appl., 5, 362-385, 1995.

Nemani, R. R., Keeling, C. D., Hashimoto, H., et al.: Climatedriven increases in global terrestrial net primary production from 1982 to 1999, Science, 300, 5625, 1560-1563, 2003.

Newman, E. I.: Resistance to water flow in soil and plant: I. Soil resistance in relation to amounts of root: theoretical estimates, J Appl. Ecol., 6, 1-112, 1969.

Noy-Meir, I.: Desert ecosystems: Environment and producers, Annu. Rev. Ecol. Syst., 4, 25-51, 1973.

Philip, J. R.: The theory of infiltration, 7, Soil Sci., 85, 333-337, 1958.

Phillip, J. R.: Theory of infiltration, Adv. Hydrosci., 5, 215-296, 1969.

Rawls, W. J., Brakensiek, D. L., and Saxton, K. E.: Estimation of Soil Water Properties, Transactions of the American Society of Agricultural Engineers, 25(5), 1316-1330, 1982.

Ritchie, J. T., Rhoades, E. D., and Richardson, C. W.: Calculating evaporation from native grassland watersheds, Transactions of the American Society of Agricultural Engineers, 1098-1103, 1976.

Rodriguez-Iturbe, I., Porporato, A., Ridolfi, L., Isham, V., and Cox, D. R.: Probabilistic modelling of water balance at a point: the role of climate, soil and vegetation, P. Roy. Soc., 455, 37893805, 1999.

Running, S. W. and Coughlan, J. C.: A general model of forest ecosystem processes for regional applications: 1. Hydrologic balance, canopy gas exchange and primary production processes, Ecol. Model., 42, 125-154, 1988.

Rutter, A. J.: The hydrological cycle in vegetation, edited by: Monteith, J. L., Vegetation and the Atmosphere, 1, Principles, Academic Press, 111-154, 1975.

Sala, O. E., Lauenroth, W. K., Parton, W. J., and Trlica, M. J.: Water status of soil and vegetation in a shortgrass steppe, Oecologia, 48, 
327-331, 1981

Sala, O. E., Parton, W. J., Joyce, L. A., and Lauenroth, W. K.: Primary production of the central grassland region of the United States, Ecology, 69, 40-45, 1988.

Salvucci, G. D. and Entekhabi, D.: Equivalent steady soil moisture profile and the time compression approximation in water balance modeling, Water Resour. Res., 30, 2737-2749., 1994a.

Salvucci, G. D. and Entekhabi, D.: Comparison of the Eagleson statistical-dynamical water balance model with numerical simulations, Water Resour. Res., 30, 2751-2757, 1994b.

Sellers, P. J., Heiser, M. D., and Hall, F. G.: Relation between surface conductance and spectral vegetation indices at intermediate $\left(100 \mathrm{~m}^{2}\right.$ to $15 \mathrm{~km}^{2}$ ) length scales, J. Geophys. Res., 97, D17, 19033-19059, 1992.

Sellers, P. J., Randall, G. J., Collatz, G. J., Berry, J. A., Field, C. B., Dazlich, D. A., Zhang, C., Collelo, G. D., and Bounoua, L.: A revised land surface parameterization ( $\mathrm{SiB} 2$ ) for atmospheric GCMs, Part I: Model formulation, J. Clim., 9, 676-705, 1996.

Sellers, W. D.: Physical Climatology. The University of Chicago Press, Chicago, 272 pp., 1965.

Shuttleworth, W. J. and Wallace, J. S.: Evaporation from sparse crops: an energy combination theory, Q. J. Roy. Meteor. Soc., 111, 839-855, 1985.

Singh, J. S., Milchunas, D. G., and Lauenroth, W. K.: Soil water dynamics and vegetation patterns in a semiarid grasland, Plant Ecology, 134, 77-89, 1998.
Stannard, D. I.: Comparison of Penman-Monteith, ShuttleworthWallace, and modified Priestley-Taylor evapotranspiration models for wildland vegetation in semiarid rangeland, Water Resour. Res., 29(5), 1379-1392, 1993.

Tellers, T. E. and Eagleson, P. S.: Estimation of Effective Hydrologic Properties of Soils from Observations of Vegetation Density. Ralph M. Parsons Laboratory for Hydrology and Water Resource Systems Report Number 254, Department of Civil Engineering, Massachusetts Institute of Technology, Cambridge, MA., (see http://ntrs.nasa.gov/search.jsp?N= 4294862922), 1980.

USDA-ARS: Hydrology, erosion, and water-quality studies in the Southern Great Plains Research Watershed, southwestern Oklahoma, 1961-78, ARS Water Quality and Watershed Research Laboratory xi, 175 pp., 1983.

Van Bavel, C. H. M., and Hillel, D. I.: Calculating potential and actual evaporation from a bare soil surface by simulation of concurrent flow of water and heat, Agr. Meteorol., 17, 453-476, 1976.

Van den Honert, T. H.: Water transport in plants as a catenary process, Discuss. Faraday Soc., 3, 146-153, 1948.

Woodward, F. I.: Climate and Plant Distribution, Cambridge University Press, Cambridge, 174 pp., 1987.

Zea-Cabrera, E., Iwasa, Y., Levin, S., and Rodríguez-Iturbe, I.: Tragedy of the commons in plant water use, Water Resour. Res. 42(4), W06D02, doi:10.1029/2005WR004514, 2006. 